\title{
Metafísica e ciência: A vontade e a analogia em Schopenhauer
}

\author{
Metaphysics and science: \\ The will and the analogy in Schopenhauer
}

\author{
Jorge Luis Palicer do Prado \\ Doutorando em Filosofia pela USP \\ E-mail: jorge.p.prado@hotmail.com
}

\begin{abstract}
Resumo: Este artigo investiga a resolução de Schopenhauer para o problema da unidade entre micro e macrocosmo que, segundo o filósofo, é o maior enigma da filosofia. Nossa atenção se volta para a modificação da doutrina kantiana da coisa-em-si e para o método analógico contidos naquela resolução. A tese da vontade como essência do mundo foi elaborada entre 1809 e 1814, período de formação científica do filósofo. Isso permitiu pensar a importância das ciências naturais no desenvolvimento do argumento analógico schopenhaueriano. A motivação maior no texto que se segue consiste em compreender o conceito de Vontade como coisa-em-si. A hipótese condutora afirma que o referido conceito foi elaborado a partir de um método de reflexão por analogia inspirado nos estudos científicos de Schopenhauer e, enquanto tal, é parte de uma visão analógica da realidade que exclui o discurso sobre qualquer princípio ontológico transcendente.
\end{abstract}

Palavras-chave: Vontade; Coisa-em-si; Analogia.

Abstract: This paper investigates Schopenhauer's resolution to the problem of unity between micro and macrocosm that, according to the philosopher, is the biggest Philosophy enigma. Our attention is toward the modification of Kantian doctrine of the thing-in-itself and to the analogical method present in that resolution. The thesis of will as world's essence was elaborated between 1809 and 1814, period of the philosopher's scientific formation. It has permitted to reflect the importance of natural sciences in the development of Schopenhauer's analogical argument. The greatest motivation in this text consists of comprehending the Will as thing-in-itself concept. The conducting hypothesis states that the referred concept was elaborated from the reflexive method by analogy inspired in Schopenhauer's scientific studies, and while that, it is part of and analogical view of the reality that excludes any ontological transcendent principle.

Keywords: Will; Thing-in-itself; Analogy.

\section{Introdução}

$$
\begin{aligned}
& \text { rthur Schopenhauer compreendeu a metafísica como a arte de } \\
& \text { decifrar o enigma do mundo, encontrando o sentido das } \\
& \text { representações intuitivas contidas na consciência do sujeito do }
\end{aligned}
$$

conhecimento, isto é, da totalidade da experiência possível. O mundo, nesta concepção, é algo assim como uma "escritura" cujo alfabeto permanece, em última análise, desconhecido para nós. Cabe, entretanto, à reflexão filosófica, a tarefa de formular uma "hipótese (Annahme)" sobre o "significado (Bedeutung)" deste conteúdo e "decifrá-lo" (Entzifferung), dando "acordo e consistência" (Übereinstimmung) à multiplicidade e 
diversidade em que se encontram ${ }^{1}$. O filósofo busca desvelar a experiência para contemplar o que o mundo é em sua essência (Wesen) íntima. À metafísica concerne, portanto, "a unidade do homem com a natureza, do microcosmo com o macrocosmo, o qual constitui o maior dos enigmas"2.

Diante da vida e do problema que nela se apresenta o homem, animal metaphysicum, sofre, se assombra e morre. A certeza da morte, "e com isso a consideração dos sofrimentos e da miséria da vida, é o que dá o impulso mais forte (stärksten Anstoß) à reflexão filosófica e às explicações metafísicas do mundo".3 Entretanto, a essência-em-si do mundo é como uma fortaleza fechada, impossível de se conquistar a partir do exterior. Schopenhauer então defende que outro caminho precisa ser tomado, algo como "uma passagem subterrânea, uma conexão secreta que nos coloca a todos de uma só vez e traiçoeiramente na fortaleza que não poderia ser tomada por um ataque exterior". ${ }^{4}$ Através do caminho subjetivo, segundo o filósofo,

o nosso ser íntimo é, em cada momento, acessível para nós, pois vemos isso como sendo a vontade, principalmente dentro de nós mesmos e a partir da mesma analogia com o nosso próprio ser, e deve ser possível para nós desvendar o restante, já que alcançar a intuição de que um ser em si, independente de ser conhecido, ou seja, de se exibir como um intelecto, só é concebível como um querer [Wollen]. ${ }^{5}$

A interpretação metafísica proposta por Schopenhauer admitiu a necessidade de

\footnotetext{
${ }^{1}$ SCHOPENHAUER, A. MVR II vol. 1, cap. 17, p. 281.

${ }^{2}$ SCHOPENHAUER, A. MP III, 240, p. 620. A metáfora do mundo como um código desconhecido ou hieróglifo aparece pela primeira vez nos textos de Schopenhauer em um manuscrito de 1812 (SCHOPENHAUER, A. MP I, § 54, p. 30-31), entretanto, conforme Arthur Hübscher, o filósofo já a conhecia entre 1806-1807 e se trata do influxo de ideias provenientes do romantismo e misticismo alemães que Schopenhauer recebera quando ainda adolescente através de Wilhelm Henrich Wackenroder, Ludwig Tieck e Zacharias Werner (HÜBSCHER, A. The philosophy of Schopenhauer in its intellectual context: Thinker against the tide, p. 43-45). Cabe também mencionar que, além das metáforas da escritura desconhecida e da fortaleza, Schopenhauer ainda se serve da metáfora indiana do véu de Maia para enfatizar o caráter de mistério que o mundo adquire quando o observamos pela perspectiva transcendental. Entretanto, não se pode perder de vista a severa oposição de Schopenhauer a algumas ideias centrais do romantismo místico, por exemplo, a divinização e espiritualização da natureza, a intuição racional capaz de conhecer o absoluto, entre outras. Em um encontro com Tieck em 1825, Schopenhauer responde à argumentação sobre a relevância de Deus para o homem questionando ironicamente: "você precisa de um Deus?" (HÜBSCHER, A. Arthur Schopenhauer Gespräche, p. 53) Marco Segala defende que Schopenhauer foi "capaz de lidar com e avaliar diferentes aspectos do Romantismo, sem sucumbir à sua encantadora difusão. O resultado foi uma concepção de natureza que, apesar das semelhanças com os românticos, demonstrou a sua independência em relação ao clima cultural daqueles anos." (SEGALA, M. Schopenhauer, la filosofia, le scienze, p. 82).
}

${ }^{3}$ SCHOPENHAUER, A. MVR II vol. 1, cap. 17, p. 250.

${ }^{4}$ SCHOPENHAUER, A. MVR II vol. 1, cap. 17, p. 299.

${ }^{5}$ SCHOPENHAUER, A. MVR II vol. 1, cap. 22, p. 403. 
um ponto de convergência entre a ciência e metafísica para que a consecução de sua tarefa própria se ajustasse às limitações do intelecto e as possibilidades do discurso. Entretanto, a metafísica dá um passo adiante em relação à consideração meramente empírica do mundo. A matéria-prima com a qual trabalha são os conceitos abstratos e, ainda que estes não possam ser a primeira coisa em nenhum conhecimento efetivo, pois são eles sempre derivados de alguma intuição", "tudo o que é fixado em conceitos se constitui como um saber, então, como tal, a filosofia é uma ciência". Em realidade "é intermediária entre a arte e a ciência, ou melhor, reúne arte e ciência". 7 Esta ambiguidade constitutiva da metafísica schopenhaueriana nos lança no centro de uma dificuldade que é um emblema seu, a saber, o ajuste da consideração metafísica do mundo com os limites do intelecto humano e as possibilidades do discurso filosófico. $\mathrm{O}$ modo ex abrupto como Schopenhauer pretendeu solucionar o problema permanece como o centro problemático de sua filosofia ${ }^{8} \mathrm{e}$, paradoxalmente, como um ponto de grande interesse na compreensão do sentido da obra do filósofo e o seu lugar na história do pensamento.

Schopenhauer argumentou que, ao estarmos diante do enigma do mundo, "é lícita toda hipótese que conduza a uma compreensão, ainda que seja esquemática ou analógica (analogischem)"," ou seja, "as coisas às quais nós não podemos chegar

\footnotetext{
${ }^{6}$ SCHOPENHAUER, A. MVR II vol. 1, cap. 17, p. 274.

${ }^{7}$ SCHOPENHAUER, A. MP I, $\S 692$, p. 533-534- 1817.

${ }^{8}$ Por exemplo, entre os críticos, podemos lembrar Nietzsche que acusa Schopenhauer de requerer um pensamento objetivo para algo que não pode nunca ser um objeto e, desse modo, enfeitar esse não-objeto desconhecido com predicados retirados da experiência objetiva e, subsequentemente, considerar os enfeites, ou predicados, como a coisa-em-si. (NIETZSCHE, F. W. Zu Schopenhauer. In C. Janaway (ed.) Willing and nothingness, p. 262). Entre os intérpretes podemos citar como exemplo Christopher Janaway para quem "Schopenhauer afirma não só que podemos saber que há uma coisa-em-si, mas também que podemos saber qual a sua natureza. Além disso, ele está preparado para usar evidências empíricas para confirmar o conhecimento metafísico de a coisa-em-si." (JANAWAY, C. Self And World in Schopenhauer's Philosophy, p. 188-189). Janaway atribui uma contradição entre teoria da representação e metafísica da Vontade e uma consequente inconsistência dessa última. "Parece que ele (Schopenhauer) só pode avançar para o conhecimento da coisa em si, negando esta parte central da teoria da representação. Schopenhauer nunca fornece uma resposta satisfatória a esta preocupação." (JANAWAY, C. Self And World in Schopenhauer's Philosophy, p. 192-193). Patrick Gardiner interpreta a questão como um "dilema", ou seja, "Se Schopenhauer afirma que na experiência interior estamos diretamente conscientes de nós mesmos como vontade, segue-se que a vontade está dentro do intervalo de nossa experiência. Mas não deve, então, ser "representação" no sentido schopenhaueriano do que é apresentado a um sujeito cognoscente? E, em caso afirmativo, como ele pode afirmar que a nossa familiaridade com ela nos dá acesso à coisa-em-si? Porque esta última, por definição, está além do reino da aparência, além do reino ilusório de representação que (seguindo o pensamento indiano), ele às vezes chama de "o véu de Maya". Se, por outro lado, a vontade não é representação, mas o numenal, como ele pode afirmar que temos experiência dela? (GARDINER, P. Schopenhauer, p. 172). A leitura dogmatizante, por assim dizer, da obra de Schopenhauer não é incomum e ganha muitos aspectos diferentes e nuances de sutileza em cada autor.
}

${ }^{9}$ SCHOPENHAUER, A. P I, p. 285. 
diretamente devem se tornar inteligíveis para nós através de uma analogia (Analogie) ${ }^{\text {10 }}$. Portanto, "o macrocosmo somente pode ser compreendido em função do microcosmo"11. "Esse emprego da reflexão", nos diz Schopenhauer, "é o único que não nos abandona no fenômeno, mas, através dele, leva-nos à COISA-EM-SI" ${ }^{12}$. O filósofo nos coloca aqui diante de uma concepção metodológica que atribui à analogia o status de ferramenta explicativa capaz de formular e apoiar hipóteses, decifrar enigmas e melhorar nossa compreensão da efetividade do mundo e daquilo que nele se manifesta.

Segundo este ponto de vista, a reflexão por analogia é uma forma filosófica, par excellence, isto é, um recurso capaz de conduzir e auxiliar a interpretação da experiência em sua totalidade nos termos que nos é mais imediatamente conhecido.

Uma analogia, por si somente, não garante a solução do problema de Schopenhauer, sua eficiência exigirá também um conteúdo que, "imediatamente iluminado pelo conhecimento" 13 , é encontrado na relação entre a vivência corporal e a contemplação estética do mundo, ou melhor, a combinação, "no lugar certo da experiência exterior com a interior, e fazendo da última a chave para a primeira" ${ }^{14}$. Não é mais natural e sensato, questiona Schopenhauer, "pensar que a ciência da experiência em geral e como tal deve também partir da própria experiência?”,15

Quando colocado no mecanismo da reflexão analógica, aquela chave, segundo Schopenhauer, permite compreender a natureza íntima do mundo, a palavra do enigma é, portanto, dada ao sujeito de modo direto ou imediato como sendo a unidade de suas atividades psíquicas e fisiológicas do organismo, a saber, a vontade. O sujeito do conhecimento, identificado com o corpo, possui na consciência a existência desse corpo "[...] como aquilo conhecido imediatamente por cada um e identificado pela palavra VONTADE." Schopenhauer defende que, "tão-somente esta, fornece-lhe a chave para o seu próprio fenômeno, manifesta-lhe a significação, mostra-lhe a engrenagem interior de seu ser, de seu agir, de seus movimentos". ${ }^{16}$

Neste caminho cabe lembrar Imannuel Kant, por quem Schopenhauer

\footnotetext{
${ }^{10}$ SCHOPENHAUER, A. MVR II vol. 1, cap. 27, p. 498.

${ }^{11}$ SCHOPENHAUER, A. MP III, 302, p. 664.

12 SCHOPENHAUER, A. MVR I, § 21, p. 168.

${ }^{13}$ SCHOPENHAUER, A. MVR I, § 22, p. 169.

${ }^{14}$ SCHOPENHAUER, A. MVR II vol. 1, cap. 17, p. 277.

${ }^{15}$ SCHOPENHAUER, A. MVR II vol. 1, cap. 17, p. 276.

${ }^{16}$ SCHOPENHAUER, A. MVR I $\S 18$, p. 157. 
manifestou grande reverência e uma acentuada ruptura para com várias de suas teses ${ }^{17}$. A “divisão da experiência entre fenômeno e coisa-em-si"18 é, dentre as ideias de Kant, o seu "maior mérito"19, pois, contém a prova da existência de um núcleo (Kernes) do fenômeno totalmente distinto das formas usadas para conhecê-lo. Na metafísica de Schopenhauer, este núcleo, toto genere distinto das representações, não pode ser "separado do fenômeno, e ser considerado por si só como um ens extramundanum, mas só é conhecido em suas relações e referências ao próprio fenômeno" ${ }^{\text {20 }}$. Diante desse conceito de coisa-em-si, Schopenhauer formula o seu controverso argumento de analogia:

todos os objetos que não são nosso corpo, [...] serão julgados exatamente conforme analogia com aquele corpo. Por conseguinte, serão tomados, precisamente como ele, de um lado como representação e, portanto, nesse aspecto, iguais a ele; mas de outro, [...] conforme sua essência íntima, tem de ser o mesmo que aquilo a denominarmos em nós VONTADE ${ }^{21}$.

A partir disso, a Vontade é considerada a coisa-em- $\mathrm{si}^{22}$. Entretanto, é crucial

\footnotetext{
${ }^{17}$ SCHOPENHAUER, A. CK, p. 523-524.

${ }^{18}$ SCHOPENHAUER, A. MVR II vol. 1, cap. 17, p. 279.

${ }^{19}$ SCHOPENHAUER, A. CK, p. 528.

${ }^{20}$ SCHOPENHAUER, A. MVR II vol. 1, cap. 17, p. 279.

${ }^{21}$ SCHOPENHAUER, A. MVR I, § 19, p. 162-163.
}

${ }^{22}$ A filosofia de Schopenhauer se insere em uma profusa discussão sobre o problema da coisa-em-si, desde que Kant o elaborou. Diversos outros pensadores do século XIX, entre defensores e críticos de Kant, alimentaram uma longa e profunda polêmica que desembocou nas filosofias conhecidas como idealismo absoluto e representadas por Johann Gottlieb Fichte (1762-1814), Friedrich Wilhelm Joseph von Schelling (1775-1854) e Georg Wilhelm Friedrich Hegel (1770-1831). Podemos citar como exemplo do contexto sobre a coisa-em-si Friedrich Heinrich Jacobi (1743-1819), Karl Leonhard Reinhold (17571823), Gottlob Ernst Schulze (1761-1833). Jacobi pode ser considerado como o primeiro crítico de Kant a inaugurar o que ficou conhecido como problema da afecção, isto é, pressupor que as coisas-em-simesmas sejam causadoras das nossas impressões. Segundo Jacobi, indo às últimas consequências, não podemos "penetrar no sistema sem aquele pressuposto (coisa-em-si) e, com ele, não podia aí permanecer" (JACOBI, F. H. Sobre o Idealismo Transcendental, In: Recepção da Crítica da Razão Pura: Antologia de escritos sobre Kant (1786-1844), p. 107). Essa contradição foi debatida por Reinhold que ofereceu uma defesa de Kant contra o problema da afecção. Reinhold argumentou que a "coisa em si e as suas qualidades, distintas da forma da representação, não só não são nada impossível, como até são algo indispensável à mera representação", ou seja, "nenhuma representação é pensável sem a coisa em si." (REINHOLD, K. L. Briefe Über die Kantische Philosophie e de Versuch einer neuen Theorie des Menschlichen Vorstellungsvermögen. In: Recepção da Crítica da Razão Pura: Antologia de escritos sobre Kant (1786-1844), p. 194). Entretanto, ao que parece o problema da afecção não se supera com o argumento de Reinhold e Schulze, por sua vez, parece reelaborar o argumento de Jacobi, reforçando um ceticismo em relação a Kant. Schulze argumenta que "O objeto para além das nossas representações (coisa em si) que, segundo a crítica da razão, terá fornecido o material das intuições através do influxo sobre a nossa sensibilidade, por sua vez, também não é em si uma intuição ou uma representação sensível, mas deve ser algo de realiter distinto e independente das mesmas; não pode, portanto, aplicar-se a esse objeto, segundo os próprios resultados da crítica da razão, nem o conceito de causa, nem tão-pouco o conceito da realidade [...]" (SCHULZE, G. E. Enesidemo. In: Recepção da Crítica da Razão Pura: 
compreender que, impedido de um conhecimento direto e absoluto da coisa-em-si, dogmaticamente exigido para uma solução definitiva e absoluta do enigma do mundo, Schopenhauer aqui elabora uma metáfora no interior de um discurso metafísico sobre o aspecto mais íntimo e subjetivo da totalidade da experiência ${ }^{23}$, algo, portanto, com valor conotativo nesse nível da exposição.

Essa COISA-EM-SI, (queremos conservar a expressão kantiana como fórmula definitiva), que enquanto tal jamais é objeto, porque todo objeto é apenas seu fenômeno e não ela mesma, se pudesse ser pensada objetivamente, teria de emprestar nome e conceito de um objeto, de algo dado de certa forma objetivamente, por consequência de um de seus fenômenos. Este, contudo, em apoio à compreensão, não poderia ser outra coisa senão o mais perfeito dentre seus fenômenos, isto é, o mais nítido, o mais desenvolvido, imediatamente iluminado pelo conhecimento: exatamente a VONTADE humana. Todavia, é preciso observar que aqui obviamente empregamos somente uma denominatio a potiori, ${ }^{24}$ mediante a qual o conceito de vontade adquire uma maior envergadura que a possuída até então. Ora, o conhecimento do idêntico em fenômenos diferentes, e do diferente em fenômenos semelhantes, é justamente, como Platão amiúde observa, a condição da filosofia ${ }^{25}$.

A Vontade como coisa-em-si, enquanto metáfora conceitual, é a expressão metafísica do significado da experiência em geral que, obtida por analogia com a vivência concreta e direta do corpo, ilumina o conhecimento apoiando a compreensão metafísica do mundo. Expandida em seu raio de aplicação a palavra Vontade significa a modificação da doutrina kantiana da coisa-em-si, pois sustenta que

se a coisa em si mesma não é absoluta e completamente conhecível, no entanto, o mais imediato de seus fenômenos, distinto toto genere [inteiramente] de todo o resto por essa imediaticidade, é o seu representante para nós. Assim temos de referir o mundo inteiro de fenômenos àquele em que a coisa em si se manifesta sob o mais leve

Antologia de escritos sobre Kant (1786-1844), p. 262-263) Fichte, Schellig e Hegel, cada um a seu modo, rejeitarem por completo a coisa-em-si e elaborarem o idealismo absoluto. Schopenhauer combateu severamente esse tipo de idealismo considerando-o como uma transgressão e um equívoco sobre a filosofia de Kant se constituindo como um non sense dogmático e patológico da filosofia alemã. Neste contexto, Schopenhauer retomou a coisa-em-si, entretanto, pretendendo evitar os resquícios dogmáticos de Kant evidenciados pelo problema da afecção e o dogmatismo inerente ao idealismo absoluto.

${ }^{23}$ Sobre a metáfora da Vontade como coisa-em-si, ver PRADO, J. L. P.: Schopenhauer e a Metáfora da Vontade como coisa-em-si, In: Metafísica e Moral, p. 189-233.

24 "Denominação conforme o mais distinto, perfeito" (SCHOPENHAUER, A. MVR I, § 22, p. 169, nota do tradutor).

${ }^{25}$ SCHOPENHAUER, A. MVR I, § 22, p. 169-170 e também em SCHOPENHAUER, A. MP III, 98, p. 36-37. 
de todos os véus, e continua a ser um fenômeno único na medida em que o meu intelecto, a única coisa capaz de conhecimento, ainda permanece sempre me distinguindo como aquele que quer, e que não abandona o conhecimento da forma do tempo, mesmo com a percepção interior ${ }^{26}$.

O modo como Schopenhauer compreende a noção kantiana de coisa-em-si não é unívoco e constituí um ponto controverso desde a primeira recepção até as interpretações mais atualizadas de sua obra. Em uma carta a Julius Frauenstädt (1813$1879)^{27}$ com data de 1852 , o filósofo deu conta de se esclarecer diretamente sobre o assunto:

\begin{abstract}
Minha filosofia não fala nunca dessas nuvens onde se aninham os cucos, mas apenas deste mundo, quer dizer, é imanente, e não transcendente; decifra o mundo presente como se tratasse de uma tábua hieroglífica (cuja chave encontrei na vontade) e mostra sua interconexão generalizada. Minha filosofia ensina o que é a representação e o que é a coisa-em-si. Mas, esta última, é a coisa-emsi apenas de uma maneira RELATIVA (relativ), a saber, enquanto relacionada com a representação, e esta é representação somente enquanto relacionada com a coisa-em-si. Além disto, a representação é um fenômeno cerebral. O que seja a coisa-em-si fora desta relação eu nuca o disse, simplesmente porque eu não sei; nela é vontade de viver $^{28}$.
\end{abstract}

Estas declarações são notadamente significativas e, neste contexto, nos interessa compreender o modo como as perspectivas da Vontade e da representação são aqui

\footnotetext{
${ }^{26}$ SCHOPENHAUER, A. MVR II vol. 1, cap. 18, p. 302. Schopenhauer, junto com Schulze, rejeita a dedução da coisa-em-si a partir do princípio de causalidade e assume um duplo ponto de vista sobre o mundo. "Pois assim como este (mundo) é, de um lado, inteiramente REPRESENTAÇÃO, é, de outro, inteiramente VONTADE. Uma realidade que fosse nenhuma dessas duas, mas um objeto em si (como a coisa-em-si de Kant, que infelizmente degenerou em suas mãos) é uma não-coisa fantasmagórica, cuja aceitação é um fogo fátuo da filosofia" (SCHOPENHAUER, A. MVR I, § 1, p. 45). Os supostos resquícios dogmáticos de Kant, quando este pressupõe a coisa-em-si "sobre uma conclusão conforme a lei de causalidade" (SCHOPENHAUER, A. CK, p. 548) e quando define a filosofia como "uma ciência $a$ partir de meros conceitos" (SCHOPENHAUER, A. P II, cap. I § 9, p. 38) foram severamente criticados por Schopenhauer, pois, "para a fundamentação dessa afirmação cardeal, todavia, nada é invocado senão o argumento etimológico da palavra metafísica. No entanto, em vista disso, teria sido preciso primeiro demonstrar que o estofo para a solução do enigma do mundo não pode absolutamente estar contido nele mesmo, [...]. Porém, enquanto isso não é provado, não temos razão alguma para estancar a nós mesmos a mais rica de todas as fontes de conhecimento, a experiência interna e externa, e operar unicamente com formas vazias de conteúdo" (SCHOPENHAUER, A. CFK, p. 537 - 538).

${ }^{27}$ Christian Martin Julius Frauenstädt (1813-1879), foi um amigo e estudioso da filosofia de Schopenhauer, referido pelo filósofo como seu evangelista, com quem trocou várias cartas de grande relevância teórica e conceitual para o interessado na vida e obra do filósofo. Foi o responsável pela publicação póstuma da obra de Schopenhauer em 6 volumes 1873-74, 2d ed. 1877. Publicou também vários outros textos sobre o filósofo incluindo cartas e comentários.

${ }^{28}$ SCHOPENHAUER, A. Correspondance complète, p. 377-378.
} 
relacionadas e qual o papel que a analogia ocupa nesse processo.

A tese da vontade como essência do mundo foi elaborada por Schopenhauer entre 1809 e $1814^{29}$, ou seja, precisamente o seu período de formação científica e filosófica. É possível supor, então, que o "pensamento único" de Schopenhauer, seu declarado "dogmatismo imanente" 30 , foi elaborado em consideração aos conhecimentos obtidos pelo estudo das ciências naturais, ensinadas na faculdade de medicina de Göttingen, primeiro curso frequentado pelo filósofo na Universidade Georgia Augusta.

Coincidentemente algumas das ciências ensinadas neste curso, se desenvolveram por meio da abordagem comparativa e da reflexão analógica, tais como, a fisiologia e a anatomia comparativas. Os conhecimentos produzidos por vários naturalistas se ajustaram às pretensões de Schopenhauer de reforçar o aspecto imanente de sua metafísica estabelecendo um ponto de contato desta com as pesquisas empíricas. A partir disso, uma intensa crítica à filosofia de modo geral é levada a cabo por Schopenhauer $^{31}$, porém, paradoxalmente o filósofo se expõe com isso a vários questionamentos sobre o estatuto de sua metafísica. Como compreender uma metafísica que discursa sobre uma coisa-em-si relativa ao fenômeno, imanente ao mundo e considerada como Vontade a partir de uma analogia com a atividade fisiológica do corpo $?^{32}$

\footnotetext{
${ }^{29}$ SCHOPENHAUER, A. MP I, p. 113.

${ }^{30}$ Schopenhauer considerou sua filosofia como um "dogmatismo imanente", um ponto médio entre a filosofia crítica de Kant e o dogmatismo transcendente (SCHOPENHAUER, A. CK, p. 538-539). Por dogmatismo imanente Schopenhauer compreende uma metafísica construída com teses dogmáticas (interpretação da diversidade fenomênica mediante a unificação desta num conceito único), "mas que não transcendem o mundo dado na experiência, mas sim que simplesmente explicam o que este é, decompondo-o em seus elementos últimos" (SCHOPENHAUER, A. P I §14, p. 159). Sendo assim, um dogmatismo imanente consiste no acordo natural das proposições com sua fonte de conhecimentos, isto é, "a captação intuitiva do mesmo objeto considerado sucessivamente desde distintos aspectos, a saber, do mundo real em todos seus fenômenos, atendendo à consciência em que se apresenta" (SCHOPENHAUER, A. P I §14, p. 159-160).

${ }^{31}$ Por exemplo, a) a confusão entre princípio de conhecimento e suas consequências com causa e efeito em Descartes e Spinoza. Este último ainda teria explicado algo desconhecido (o mundo) por algo ainda mais desconhecido (Deus) e permanecendo dissonante com a existência da corrupção moral e do sofrimento; b) as inconsequências e traços dogmáticos que Kant teria abrigado no modo como deduz a pressuposição da coisa-em-si sobre a lei de causalidade e c) as filosofias do absoluto de Fichte, Schelling e Hegel, que se apoiaram eu uma suposta capacidade da razão conhecer o absoluto, interditada pelo próprio Kant.

${ }^{32}$ Arthur Hübscher explica que "há uma confluência do sentido real e do sentido pictórico que confere à apresentação de Schopenhauer, o verdadeiro brilho e clareza [...]. Cada local revela seu verdadeiro significado último apenas na interdependência de sentido, quando retirado do contexto [...], torna-se ambígua, erróneo, falso. As objeções contra o sistema, as dificuldades e contradições que as pessoas quiseram encontrar nele, são sempre novamente rastreáveis para a alternância entre os dois métodos diferentes de observação. (HÜBSCHER, A. The philosophy of Schopenhauer in its intellectual context: Thinker against the tide, p. 381). Maria Lúcia Cacciola esclarece que "o ponto de vista da representação Metafísica e ciência: a vontade e a analogia em Schopenhauer 
Revista Voluntas: Estudos sobre Schopenhauer - Vol. 6, № 1 - $1^{\circ}$ semestre de 2015 - ISSN: 2179-3786 - pp. 44-84.

A formação científica de Schopenhauer e os impactos desta na obra do filósofo fazem parte do interesse desta pesquisa. Neste caminho, destacamos a fisiologia e a anatomia comparativas de Johann Friedrich Blumenbach, seu primeiro professor na faculdade de medicina, por oportunizar a reflexão sobre o papel do organismo na compreensão da natureza e o uso da analogia nas ciências. Nossa hipótese condutora afirma que o conceito de Vontade como coisa-em-si foi elaborado a partir de um método de reflexão por analogia inspirado nos estudos científicos de Schopenhauer e, enquanto tal, é parte de uma visão analógica da realidade que exclui o discurso sobre qualquer princípio ontológico transcendente.

\section{Schopenhauer e a faculdade de medicina}

Schopenhauer se dedicou durante toda sua vida ao estudo das ciências naturais, se empenhou em obter uma formação científica significativa, desenvolveu e publicou um trabalho científico sobre ótica fisiológica que alcançou certo reconhecimento nos círculos científicos da época ${ }^{33}$.

O interesse do filósofo pela ciência pode ter começado ainda muito jovem quando viajou pela Europa com os pais entre 1803 e $1804^{34}$, mas sua formação científica se iniciou no ano de 1809, na faculdade de medicina de Göttingen.

A Universidade Georgia Augusta de Göttingen foi um dos maiores centros de estudos em ciências físicas e biológicas da Alemanha desde a segunda metade do século XVIII, foi fundada em 1734, pelo rei inglês George Augusto II de Hannover, e foi administrada por personalidades que defenderam uma ênfase empirista e científica na formulação do programa educacional da universidade e na escolha dos professores que,

em seus dois aspectos exige o da Vontade, cujas duas facetas, a afirmativa e a negativa, só tem sentido em relação ao da representação" (CACCIOLA, M. L. O. Schopenhauer e a questão do dogmatismo, p. 25). E. Brandão acrescenta que "a ideia de Vontade como coisa-em-si muitas vezes passa por não ser nada além de uma interpretação grosseira de Kant, posição esta que esconde o embate que Schopenhauer trava com o idealismo alemão" (BRANDÃO, E. A concepção de matéria na obra de Schopenhauer, p. 338).

${ }^{33} \mathrm{O}$ trabalho Sobre a Visão $e$ as Cores possui um caráter científico e experimental de ótica fisiológica reconhecido pela literatura em torno da obra do filósofo. Sobre a Visão e as Cores foi fruto de um intenso debate com Johann Wolfgang von Goethe que introduziu o filósofo na experimentação científica. A pesquisa de Schopenhauer sobre o tema foi publicada em um compêndio de escritos oftalmológicos de Justus Radius.

${ }^{34} \mathrm{Na}$ ocasião o jovem Arthur Schopenhauer teve a oportunidade de receber explicações do renomado astrônomo William Herschel $(1738$ - 1822) sobre seus telescópios em Londres. Em Paris, pouco tempo depois, Schopenhauer conheceu o Museu de Ciências Naturais onde pôde contemplar uma exposição completa da história das ciências naturais. As impressões de Schopenhauer estão publicadas em seus Diários de viagem. 
além da docência, ali deveriam se dedicar também à pesquisa científica pura. ${ }^{35} \mathrm{Com}$ um corpo docente de grande relevância, a Georgia Augusta logo se tornou uma referência nas ciências biológicas. Johan Friedrich Blumenbach contribuiu ativamente para tornála um centro de atração para aqueles que buscavam uma formação sólida em ciências naturais. A comunidade universitária contava também com uma estrutura física, suporte técnico e tecnológico de grande porte capazes de garantir alguns dos principais avanços científicos dos séculos XVIII e XIX ${ }^{36}$.

Segundo Safranski, "é aqui que Schopenhauer iniciou o ritmo de vida que manterá até a velhice" ${ }^{\text {37 }}$. O currículo do filósofo revela seu intenso interesse e pesquisa sobre as ciências e a filosofia no período em que ficou em Göttingen e descreve que sua dedicação às ciências,

não foi tempo perdido, pois as lições que assisti são muito necessárias e proveitosas para os filósofos. Durante os dois anos que vivi em Göttingen me consagrei aos estudos com a constante aplicação à qual já estava acostumado, sem deixar que o trato com os demais estudantes, me apartasse o mínimo dos estudos. [...] Durante esses dois anos assisti as lições de G. E. Schulze, sobre lógica, metafísica e psicologia; as de Thibaut sobre matemáticas; as de Heeren sobre história antiga e contemporânea, assim como história da etnologia e etnografia; as lições de Lüder sobre história política; as de Blümenbach sobre história natural, mineralogia, fisiologia e anatomia comparada; as de Hempel sobre a anatomia humana; as de química de Strohmeier; as de física e astronomia física de Tobias Maier e as de botânica de Schrader. A estes homens excelentes tenho que mostrar meu agradecimento pelo muito que aprendi em suas lições ${ }^{38}$.

É interessante notar que Schopenhauer, tempos depois, veio a fazer críticas sérias a alguns professores de filosofia, enquanto seus professores de ciência recebem do filósofo reconhecimento e reverência. Entre eles Blümenbach ocupa uma posição de destaque já que, além do prestígio no cenário científico acadêmico e obras de grande influência, oportunizou a Schopenhauer suas primeiras reflexões sobre a ciência, dando

\footnotetext{
35 Por exemplo, Gerlach Adolph von Münchausen (1688 - 1770) e Albrecht von Haller (1708-1777).

${ }^{36}$ Segundo Luigi Marino (I maestri della Germania - Göttigen 1770-1820, p. 9-10) e Fabio Grigenti (Natura e rapresentazione: Genesi e strutura della natura in Arthur Schopenhauer, p. 62-63), a universidade em 1809 contava com um acervo bibliográfico de mais duzentos mil exemplares, de um museu (Königliches akademisches Museum), de um jardim botânico entre os mais importantes da Europa, laboratórios de química e física, e um observatório de grande relevância para a pesquisa astronômica. Com esse perfil o estudante de Göttingen podia contar com as mais avançadas técnicas e tecnologias disponíveis para pesquisa natural.

${ }^{37}$ SAFRANSKI, R. Schopenhauer e os anos selvagens da filosofia, p. 194.

${ }^{38}$ SCHOPENHAUER, A. Correspondance complete, p. 68. 
Revista Voluntas: Estudos sobre Schopenhauer - Vol. 6, № 1 - $1^{\circ}$ semestre de 2015 - ISSN: 2179-3786 - pp. 44-84.

ensejo às questões metafísicas mais relevantes que ocupam o centro da filosofia de Schopenhauer.

\section{Blumenbach: fisiologia, anatomia e Impulso Formativo}

Johann Friedrich Blumenbach também foi aluno da Georgia Augusta (1772) e depois se tornou professor de história natural, mineralogia, fisiologia e anatomia comparada na faculdade de medicina da mesma instituição (1778), sendo professor de Schopenhauer neste curso entre os anos de 1809-1811. Sua presença foi crucial para o desenvolvimento da universidade como polo de pesquisas científicas e "um ambiente cultural que poderia competir com as instituições acadêmicas que Schopenhauer tinha conhecido em Paris e Londres"39. Denominado "magister Germaniae”, foi um professor capaz de instigar as reflexões mais profundas em seus alunos e contribuir de forma ativa com outros pesquisadores. O carisma de Blumenbach aumentou consideravelmente sua fama e o poder de influência de seu pensamento sobre a comunidade de estudantes de Göttingen. ${ }^{40}$ Segundo Marco Segala, foi "Blumenbach que sugeriu a Schopenhauer a ideia de uma intima colaboração entre pesquisa fisiológica e especulação filosófica e forneceu as ferramentas conceituais para ler e compreender a literatura científica sobre fisiologia"41.

Além das aulas que Schopenhauer assistiu, o filósofo possuía alguns dos mais importantes livros de Blumenbach em sua biblioteca particular ${ }^{42}$ e, conforme Segala, estes manuais foram responsáveis por fornecer uma compreensão profunda e permanente sobre a fisiologia, além de "ideias e conceitos que alimentaram e

\footnotetext{
${ }^{39}$ SEGALA, M. Auf den Schultern eines Riesen Arthur Schopenhauer als Student Johann Friedrich Blumenbachs. In: STOLLBERG, J. und BÖKER, W. (Hg.): „, ... die Kunst zu sehn “ Arthur Schopenhauers Mitschriften der Vorlesungen Johann Friedrich Blumenbachs (1809-1811), p. 24.

${ }^{40}$ Ver MARINO, L.: I maestri della Germania - Göttigen 1770-1820, p. 65; 1975; LENOIR, T. The Gottingen School and the Development of Transcendental Naturphilosophie in the Romantic Era, p. 115; VOLPICELLI, I. A. Schopenhauer: La Natura Vivente e le sue Forme, p. 20; GRIGENTI, F. Natura e rapresentazione: Genesi e strutura della natura in Arthur Schopenhauer, p. 65-66; SEGALA, M.: Auf den Schultern eines Riesen Arthur Schopenhauer als Student Johann Friedrich Blumenbachs. In: STOLLBERG, J. und BÖKER, W. (Hg.): „, ... die Kunst zu sehn “ Arthur Schopenhauers Mitschriften der Vorlesungen Johann Friedrich Blumenbachs (1809-1811), p. 24.

${ }^{41}$ SEGALA, M. The Role of Physiology in Schopenhauer's Metaphysics of Nature. In: Schopenhauer Jahrbuch, 93 (2012), p. 330.

${ }^{42}$ De acordo com o volume V da edição de Hubscher (1985, p. 239-240) para os manuscritos de Schopenhauer, o filósofo possuía em sua biblioteca particular as obras: Ueber den Bildunsgtrieb und das Zeugungsgescäfte (1791), De generis humani varietate nativa (1756), Handbuch der vergleichenden Anatomie und Physiologie (1805), Handbuch der Naturgeschichte (1807) e Institutiones physiologicae (1810).
} 
enriqueceram seu discurso filosófico de uma maneira única"43.

Blumenbach, que se autodenominava "Physikus", não aceitava as elevadas abstrações da metafísica transcendente tradicional. Segundo Safranski, o naturalista considerava que a ciência era plenamente capaz de encontrar as respostas para todas as questões finais. "A física de Blumenbach pretendia satisfazer igualmente todas as questões propostas pela curiosidade metafísica". ${ }^{44}$ Isso se tornou um ponto de objeção do jovem estudante a seu mestre, pois, partindo do ponto de vista filosófico, Schopenhauer defendeu, no entanto, que a ciência que sustentar tais pretensões carecerá de uma visão geral sobre a natureza e padecerá por ignorância dos seus próprios pressupostos metodológicos. Apesar dessa diferença, o contato com Blumenbach ofereceu a Schopenhauer uma parte significativa do conteúdo cultural científico contido em sua reflexão sobre a natureza e o significado do mundo. Em 1819, ano da primeira publicação de sua obra principal, Schopenhauer enviou uma carta a seu antigo mestre onde expressa sua "veneração" 45 e, acompanhando o cientista, considerou a fisiologia como uma ciência interdisciplinar capaz de conduzir a investigação aos limites da compreensão sobre os fenômenos naturais ${ }^{46}$.

\footnotetext{
${ }^{43}$ SEGALA, M. The Role of Physiology in Schopenhauer's Metaphysics of Nature. In: Schopenhauer Jahrbuch, 93 (2012), p. 35 e 40. Ainda de acordo com o pesquisador (SEGALA, M. Schopenhauer, la filosofia, le scienze; p. 220-221), Blumenbach, entre 1809 e 1810, ministrou um curso de história natural com exposição das teorias de A. Haller e Charles Bonnet, um curso de mineralogia sobre Jean André De Luc (1727-1817), René Just Haüy (1743-1822) e George Louis Leclerc conde de Buffon (1707-1788), um de anatomia comparada e fisiologia sobre A. Haller (1708-1777), Peter Camper (1722-1789), Franz Joseph Gall (1758-1828) e Johann Kasper Lavater (1741-1801) e um de fisiologia onde discutiu sobre vitalismo e materialismo "à luz das concepções de Johann Christian Reil (1759-1813), Johann Wilhelm Ritter (1776-1810), Paul Joseph Barthez (1734-1806), Jean Baptiste Duhamel (1624-1706), Hermann Boerhaave (1668-1738) e William Harvey (1578-1657). Além das aulas de Blumenbach, Segala descreve o conteúdo de outros cursos, com por exemplo, o curso de Johann Tobias Mayer sobre Newton, o curso de Botânica de Heinrich Adolf Schrader, de química de Friedrich Stromeyer (1776-1835) sobre Lavoisier e seu desenvolvimento em Humphry Davy (1778-1829), Joseph Louis Gay-Lussac (1778-1850), ClaudeLouis Berthollet (1748-1822) e Jöns Jacob Berzelius (1779-1848), o curso de matemática de Bernhard Friedrich Thibaut (1775-1832), anatomia humana de Adolph Friedrich Hempel (1767-1834) e Conrad Johann Martin Langenbeck (1776-1851). Atualmente os apontamentos de Schopenhauer às aulas de Blumenbach estão organizadas e publicadas por STOLLBERG, J. e BÖKER, W. (2013). Além dos cientistas mencionados aqui e estudados por Schopenhauer em Göttingen e Berlim, somam-se ainda outros tantos que o filósofo estudou durante sua vida. A lista dos livros da biblioteca particular de Schopenhauer foi publicada por Arthur Hübscher em Handschriftlichen Nachlass, Vol V, e contém 196 obras científicas divididas entre 161 autores. Existe ainda uma lista de livros que Schopenhauer emprestou da biblioteca de Weimar publicada em Schopenhauer Jahrbuch 1923-1925 que podem ser consultadas.

${ }^{44}$ SAFRANSKI, R. Schopenhauer e os anos selvagens da filosofia, p. 195.

${ }^{45}$ SCHOPENHAUER, A. Correspondance complète, p. 55.

${ }^{46}$ As anotações de Schopenhauer referentes às aulas de Blumenbach sobre anatomia e fisiologia comparadas fornecem, neste ponto, os detalhes sobre a argumentação do cientista acerca da relevância dessas ciências e do método analógico para a elaboração de um conhecimento sistemático do funcionamento e desenvolvimento histórico da natureza e, desse modo, uma compreensão profunda sobre 
Além do próprio Schopenhauer, Kant também já havia reconhecido o esforço de Blumenbach na reunião de mecanicismo e teleologia, além da relevância do conceito de Impulso Formativo (Bilgungstrieb) na história natural. Kant cita o naturalista elogiosamente na sua Crítica da faculdade do juízo (1993, § 81, p. 265), em uma nota ao texto Acerca do uso de princípios teleológicos em filosofia (1788). Nestes textos o filósofo afirma que o cientista "trouxe luz à ciência da geração"47 e, em 1790, agradece a "instrução" que recebera dos trabalhos de Blumenbach em uma carta datada em 05 de agosto $^{48}$. O reconhecimento positivo entre o naturalista e o filósofo foi recíproco. ${ }^{49}$ Neste contexto, parece plausível pensar que, apesar de ter sido Gottlob Ernst Schulze ${ }^{50}$ quem recomendou Platão e Kant a Schopenhauer, este último entrou em contato com

o mundo natural. (STOLLBERG, J. und BÖKER, W. ,. ... die Kunst zu sehn “ Arthur Schopenhauers Mitschriften der Vorlesungen Johann Friedrich Blumenbachs (1809-1811), p. 91)

${ }^{47}$ Apud SANTOS, L. R. A formação do pensamento biológico de Kant. In: MARQUES, U. R. A.: Kant e a Biologia, p. 52.

${ }^{48}$ ZWEIG, A. (Translated and Edited), Immanuel Kant: Correspondence, p. 354.

${ }^{49}$ Conforme Leonel Ribeiro dos Santos, "o reconhecimento era recíproco" (SANTOS, L. R. A formação do pensamento biológico de Kant. In: MARQUES, U. R. A.: Kant e a Biologia, p. 57). Johann Heinrich I. Lehmann numa carta de 1799 a Kant diz que "[o] senhor Blumenbach assegurou expressamente que só através dos vossos pequenos ensaios e particularmente daquele sobre raças humanas é que começou a dar atenção a muitas coisas em que antes não tinha pensado nem chegaria a pensar tomando por base apenas os relatos de viagem e as suas observações. (apud SANTOS 2012, p. 57) A relação entre Kant e Blumenbach, "constitui porventura um dos casos mais felizes que a história das ideias registra de espontâneo e fecundo encontro entre as perspectivas de um filósofo, que interroga as condições a priori e a legitimidade transcendental dos princípios e conceitos envolvidos num especial domínio de conhecimento humanos, e o naturalista e investigador de campo, que procura uma explicação satisfatória para os fenômenos que se lhe deparam, socorrendo-se da observação e de experimentos criteriosamente orientados." (SANTOS, L. R. A formação do pensamento biológico de Kant. In: MARQUES, U. R. A.: Kant e a Biologia, p. 50).

${ }^{50}$ Gottlob Ernst Schulze (1761-1833), foi um importante filósofo e professor da Universidade Georgia Augusta de Göttingen que contribuiu ativamente para o debate filosófico em torno do kantismo e da problemática noção de coisa-em-si. Schulze ficou conhecido pela posição cética em relação a Kant publicada em uma curiosa e influente obra intitulada: Enesidemo, ou sobre os fundamentos da Filosofia Elemental oferecida pelo Sr. Professor Reinhold de Jena. Acompanhado de uma defesa do ceticismo frente as pretensões da Crítica da Razão (1792). Schulze é reconhecidamente o responsável por recomendar a Schopenhauer as leituras de Platão e Kant, fato este que, por si só, é digno de atenção. O grande desapontamento de Schopenhauer se deu com a direção que tomou o engenhoso argumento cético de Schulze, ou seja, se refere ao uso inadequado desse argumento para negar a existência da coisa-em-si no idealismo absoluto alemão. Para Schopenhauer, os idealistas usam o argumento contra a demonstração da coisa-em-si kantiana para negar existência da coisa-em-si. Entretanto, apesar dos "engenhosos argumentos de Schulze" mostrarem a "imperfeita apresentação de Kant" e, desse modo abrir caminho para os idealistas, o significado mais profundo da doutrina kantiana, a saber, a distinção entre fenômeno e coisa-em-si, permanece intacto para a consideração filosófica. (SCHOPENHAUER, A MP III, 302, p. 711). Não se pode, porém, perder de vista que a relação de Kant com Blumenbach foi significativa e já começara a apresentar os primeiros esboços da compreensão que Schopenhauer veio a formular sobre o mundo natural e, desse modo, ainda que implicitamente, incluía já nos estudos de físiologia e anatomia comparativas, ideias de origem e espírito kantiano. Segundo nossa compreensão atual, Blumenbach foi responsável oferecer uma reflexão sobre a ciência e a analogia e Schulze por oferecer um problema filosófico de grande profundidade e envergadura a Schopenhauer que, reformulou a metafísica em termos analógicos a partir imanência das atividades fisiológicas do organismo. Neste sentido, cabe observar que Blumenbach e Schulze apresentaram, respectivamente, uma visão simpática e uma cética em relação à doutrina de Kant. 
algumas ideias de Kant primeiramente por meio do "teleomecanicismo" 51 de Blumenbach. Apesar de não haver uma aceitação consensual na universidade Georgia Augusta $^{52}$, Blumenbach foi um dos professores a introduzir as primeiras discussões sobre Kant em Göttingen. Além disso, o desenvolvimento do método comparativo em história natural e a teoria do Impulso formativo (Bildungstrieb), foram centrais no programa pedagógico do naturalista e, neste sentido, ampliaram consideravelmente os conhecimentos de Schopenhauer sobre o mundo natural.

Segundo Blumenbach, impulso formativo, assim como ocorre com palavras como atração, gravidade, significa "um poder constante cujo efeito é reconhecido pela experiência e cujas causas, como as causas do referido e os geralmente reconhecidos poderes naturais são, para nós, uma qualitas occulta"53. Esclarece que, "este impulso (tendência, esforço, ou como quiser chamá-lo), [...] mostra-se como uma das causas primeiras de

\footnotetext{
${ }^{51}$ T. Lenoir denomina teleomecanicismo a reunião dos dois modelos de interpretação da natureza com a qual, segundo o intérprete, Kant e Blumenbach puderam contribuir mutuamente para o programa científico de Göttingen, ou seja, "A importância da obra de Kant não consistia em propor hipóteses ou um sistema da natureza orgânica para qual Blumenbach tentou fornecer suporte empírico; nem se pode argumentar que Blumenbach se imaginava um seguidor de Kant. O trabalho dos dois homens, ao contrário, era de apoio mútuo ao mesmo programa, o programa que eu chamo de filosofia transcendental da natureza da Escola de Göttingen" (LENOIR, T. The Gottingen School and the Development of Transcendental Naturphilosophie in the Romantic Era, p. 144). Entretanto essa opinião não é consenso. Existem discussões que atribuem um valor constitutivo e não meramente regulativo ao conceito de Bildunstrieb. Compare, por exemplo, LENOIR, T.: The Strategy of Life: Teleology and Mechanics in Nieneteenth-Century German Biology. The University of Chicago Press - Chicago-London, 1982 e RICHARD, R. J.: Kant and Blumenbach on the Bildungstrieb: A Historical Misunderstanding. Stud. Hist. Phil. Biol. \& Biomed. Sci., Vol. 31, No. 1, p. 11-32.

${ }_{52}$ Por exemplo, Johann Friedrich Herbart e Schulze sustentaram visões severamente críticas sobre Kant e o kantismo subsequente.

${ }^{53}$ BLÜMENBACH, J. F.: An essay on generation, p. 21. O termo qualitates occultae, ou no singular qualitas occulta, teve seu desenvolvimento na filosofia medieval e, segundo Wouter J. Hanegraaff, o conceito "passou a desempenhar um papel fundamental no projeto de emancipar as ciências antigas do domínio da superstitio, e legitimando-o como magia naturalis. A razão é que isto forneceu um argumento científico convincente para afirmar que muitos "fenômenos maravilhosos da natureza", que as pessoas comuns tendem a atribuir à agência demoníaca ou sobrenatural, eram de fato puramente naturais. Em outras palavras longe de sugerir uma visão de mundo "ocultista" de acordo com o entendimento moderno desse termo, que era originalmente um instrumento de desencanto, usado para retirar o reino do maravilhoso do controle teológico e torná-lo disponível para o estudo científico" (HANEGRAAFF, W. J., Esotericism and Academy: rejected knowledge in western culture p. 180). Schopenhauer, por sua vez, estava ciente quanto a um possível abuso do termo e se opõe a ele de forma clara: "A essência comum e universal de todos os fenômenos de uma determinada espécie, aquilo sem cuja pressuposição a explanação por causas não teria sentido nem significação, é justamente a força da natureza em geral, que tem de permanecer na física como qualitas occulta, precisamente porque aí finda a explanação etiológica e começa a explanação metafísica" (SCHOPENHAUER, A. MVR I, § 27, p. 203). Em Schopenhauer, qualitas occulta significa uma força natural (Naturkraft) originária, isto é, uma força que não se pode remeter a uma causa anterior e, desse modo, não está aberta à consideração da ciência e sim pressuposta nesta. Trata-se das manifestações mais primitivas da natureza que Schopenhauer compreenderá, segundo o assunto, como forças naturais, grau elementar de objetivação da vontade e Ideias platônicas. Schopenhauer teve como fonte para o uso do termo qualitas occulta a física de Newton, que compreende a gravidade como uma qualidade oculta da matéria e a fisiologia e anatomia comparativas de Blümenbach onde o impulso formativo (Bildungstrieb) é compreendido do mesmo modo.

Metafísica e ciência: a vontade e a analogia em Schopenhauer 
toda geração, nutrição e reprodução" ${ }^{\text {"54 }}$. Portanto, o conceito de impulso formativo, não explica nada sobre o núcleo em-si da natureza, mas, ao contrário,

tem a intenção de designar uma força particular cujo efeito constante é reconhecida a partir do fenômeno na experiência, mas cuja causa, nos resta como qualidade oculta. Isso não nos impede de forma alguma, no entanto, de tentar investigar os efeitos dessa força através de observações empíricas e para trazê-los sob uma lei geral ${ }^{55}$.

Neste sentido, o Impulso formativo, enquanto uma metáfora científica com funções heurísticas e regulativas para as investigações biológicas, descreve as múltiplas atividades próprias dos fenômenos da vida em geral e as reúne em um conceito único capaz de nos levar aos limites da explicação empírica, até as qualidades ocultas da matéria orgânica.

Em Göttingen as discussões sobre a metodologia mais eficiente para a compreensão do universo, sobretudo no período em que Schopenhauer lá estudou, foram em grande parte derivadas da filosofia de Kant. Blumenbach foi, neste contexto, um dos primeiros a introduzir a abordagem comparativa e a reflexão analógica como partes integrantes do seu método de estudo e ensino sobre a história natural. $\mathrm{O}$ naturalista se tornou cada vez mais convencido de que a análise comparativa e a reflexão analógica em anatomia e fisiologia eram a "alma viva da história natural" influência direta de Kant em relação à racionalidade e à metodologia científica e filosófica impulsionou Blumenbach e considerar que, destituído do poder intuitivo de conhecer diretamente a natureza interna das coisas, o pesquisador deve compreender que "o único caminho para o conhecimento é construir o sistema geral da natureza

\footnotetext{
${ }^{54}$ BLÜMENBACH, J. F. Über den Bildungstrieb und das Zeugungsgeschäfte, p. 13.

${ }^{55}$ BLÜMENBACH, J. F. Handbuch der Naturgeschichte: nebst zwey Kupfertafeln, p. 19.

56 BLÜMENBACH, J. F., Handbuch der vergleichenden Anatomie, p. 5-6. Segundo Fabio Grigenti, Blumenbach "foi o primeiro professor universitário a utilizar a anatomia comparada como parte integrante do seu método de ensinamento" (GRIGENTI, F. Natura e rapresentazione: Genesi e strutura della natura in Arthur Schopenhauer, p. 65). Dentro da história do desenvolvimento do que hoje denominamos ciências biológicas, a epistemologia do método analógico conduziu os esforços dos pesquisadores a questionamentos e descobertas sobre a vida que, além de solapar as bases metafísicas e ideológicas da ciência, nutriram a compreensão filosófica da natureza de modo geral. Perrier explica que, "muitas vezes, o método mais antigo, que os físicos às vezes se referem de modo um pouco desdenhoso como o método dos naturalistas, continua a introduzir discórdia sobre os princípios fundamentais e os corolários derivados deles. Ao estudar as obras de naturalistas famosos, fica-se impressionado pelas grandes diferenças entre os seus métodos e os dos físicos. Essas diferenças residem muito menos no uso de observações subjetivas em vez de experimentação objetiva do que na prática costumeira de físicos, que vão do simples ao complexo, em seus esforços para relacionar os efeitos às suas causas próprias. Por muitos anos, os naturalistas se limitaram a comparação, enquanto os cientistas físicos estavam se esforçando para explicar as coisas" (PERRIER, E. The Philosophy of Zoology Before Darwin, p. 18).
} 
através de uma análise comparativa" ${ }^{, 57}$. Assim, o método analógico proposto por Blumenbach fornecia um exame comparativo

a) da forma externa, b) da estrutura (fábrica) interna, c) da função da economia animal, d) dos dotes mentais, e) das doenças que são próprias do homem e, finalmente, f) da variedade de pontos de vista, (vulgar et false), que o próprio homem tinha elaborado sobre o seu relacionamento com os outros animais ${ }^{58}$.

Isto nos permite supor que Schopenhauer começou a formular sua interpretação da obra de Kant, ainda que indiretamente, primeiramente através de Blumenbach. Além disso, o decidido imanentismo de Schopenhauer, isto é, a ideia de que os fatos naturais devem ser a terra firma ou o ponto de partida de qualquer compreensão filosófica significativa, tem sua origem mais remota e maior estimulo nas aulas de Blumenbach ${ }^{59}$. A ciência de Blumenbach forneceu a visão de que a análise comparativa e a reflexão analógica poderiam concentrar a ciência e a metafísica em um elo metodológico capaz de, com a chave certa, produzir um conhecimento mais íntimo da natureza sem, entretanto, transcender os limites do fenômeno.

A introdução do método analógico no contexto da investigação da história natural é importante para compreender a concepção de Schopenhauer sobre o valor epistemológico e metodológico da analogia, tanto em seu uso científico quanto metafísico. A anatomia e a fisiologia comparativas de Blumenbach formam o início de uma visão de mundo analógica que Schopenhauer reelaborou em termos metafísicos. Neste sentido, explica Marco Segala, “a comparação (Vergleichen) foi a chave para o acesso ao contexto e um conhecimento para além dos limites da mera descrição da natureza" ${ }^{60}$. A visão de Blumenbach sobre Kant, sobre o método analógico e o conceito de impulso formativo, são fatores fundamentais para o desenvolvimento da filosofia de Schopenhauer, especialmente no que concerne a um problema que o filósofo abraçou definitivamente pouco tempo depois através de Schulze, a saber, o problema da filosofia crítica sobre a coisa-em-si.

\footnotetext{
${ }^{57}$ LENOIR, T. The Gottingen School and the Development of Transcendental Naturphilosophie in the Romantic Era, p. 120.

${ }^{58}$ MARINO, L. I maestri della Germania - Göttigen 1770-1820, p. 113-114.

${ }^{59}$ Ver HÜBSCHER, A. The philosophy of Schopenhauer in its intellectual context: Thinker against the tide, p. 160-162; VOLPICELLI, I. A. Schopenhauer: La Natura Vivente e le sue Forme, p. 52.

${ }^{60}$ SEGALA, M. The Role of Physiology in Schopenhauer's Metaphysics of Nature. In: Schopenhauer Jahrbuch, 93 (2012), p. 31. 
Revista Voluntas: Estudos sobre Schopenhauer - Vol. 6, № 1 - $1^{\circ}$ semestre de 2015 - ISSN: 2179-3786 - pp. 44-84.

Portanto, nos parece claro que a ciência e as aulas de Blumenbach estimularam Schopenhauer a encontrar um problema para o qual a metafísica da Vontade foi posta como resposta. Schopenhauer, no entanto, não foi um aluno passivo, ao contrário, fez duras críticas às pretensões fisicalistas absolutas da ciência da época. O conceito de Impulso formativo, enquanto conceito extraído da observação e posto como causa de determinados fenômenos orgânicos, não pode solucionar a principal questão filosófica, ainda que tenha sido importante por oferecer conhecimentos revigorantes para a filosofia.

Dada a insuficiência científica em conhecer a natureza interna das coisas, o teleomecanicismo blumenbachiano, consumado pelo conceito de impulso formativo, será, em Schopenhauer, um dos objetos da metafísica da natureza, isto é, um dos principais enigmas do mundo natural. O Impulso formativo é o princípio heurístico que, aos olhos de Schopenhauer, necessita de um fundamento metafísico que lhe dê sentido. Ou seja, a metafísica da Vontade como coisa-em-si, em contraste com sua aparência fenomenal, diz Schopenhauer, leva-nos a compreender, ou pelo menos a perceber, em certo grau, uma "compatibilidade" para a "contradição" entre "o mecanismo e a técnica da natureza, em outras palavras, do mecânico com a explicação teleológica de seus produtos"61.

\section{Schopenhauer e as ciências naturais}

Schopenhauer não foi só um entusiasta, mas suas reflexões também contêm criticas limitadoras e regulativas às ciências de modo geral, além de possuir outras pretensões metafísicas. O princípio de causalidade, fio condutor da investigação científica, de acordo com o filósofo, não pode conduzir a um resultado metafísico verdadeiro já que sua aplicação legítima se limita à relação entre as representações e não ao seu significado geral. Pensar que o mundo tenha "um significado meramente físico é o erro máximo, o mais funesto e fundamental" ${ }^{12}$, um sentido metafísico é exigido e, portanto, o método e a forma das ciências em geral, não podem conduzir a uma solução satisfatória para o problema. Uma explicação do mundo meramente "física, em geral, e como tal, sempre requer qualquer coisa de ordem metafísica, que poderia fornecer a

\footnotetext{
${ }^{61}$ SCHOPENHAUER, A. MP IV, 99, p. 233-224.

${ }^{62}$ SCHOPENHAUER, A. P II, cap. 8, §109, p. 221. 
chave para todos os seus pressupostos" $"$. As formas transcendentais do conhecimento exigirão um conteúdo e, segundo Schopenhauer,

é exatamente aí que a filosofia retoma as rédeas e considera as coisas segundo um modo específico, inteiramente diferente do científico. [...] O que as ciências pressupõem como fundamento e limite das suas explanações é justamente o verdadeiro problema da filosofia, que consequentemente, principia lá onde as ciências se detêm ${ }^{64}$.

Note-se que aqui, embora a ênfase esteja sobre a insuficiência da ciência na decifração do enigma da experiência, não se oculta a importância da mesma para a consecução dessa tarefa. A ciência e a metafísica se conectam para solucionar o problema da experiência em geral $^{65}$.

São possíveis, portanto, discernir dois sentidos para a ciência na obra de Schopenhauer: O primeiro é o de "facilitação do saber" avanços na física só farão com que a necessidade de um sistema de metafísica seja sentida mais e mais, $[\ldots]^{, 67}$. O segundo sentido para a ciência está na crença de que os dados fornecidos por ela significaram uma confirmação às ideias metafísicas centrais de Schopenhauer $^{68}$. Isso certamente torna a relação entre metafísica e ciência algo ainda mais interessante e problemático, já que pressupõe o desenvolvimento de um modelo teórico de confirmação e uma filosofia da ciência no interior da Metafísica da Vontade. O conhecimento científico, nos diz Schopenhauer, quando

corrigido, ampliado e mais profundo da natureza é o próprio conhecimento que sempre enfraquece e finalmente derruba os pressupostos metafísicos que até então tinham prevalecido. Por outro lado, tal conhecimento apresenta o problema da metafísica em si mesma mais clara, correta e completamente, e separa isto mais distintamente de tudo que é meramente físico ${ }^{69}$.

A metafísica precisa manter uma conexão com os problemas e as pesquisas empíricas para não transcender o limite do conhecimento possível e postular

\footnotetext{
${ }^{63}$ SCHOPENHAUER, A. MVR II vol. 1, cap. 17, p. 266.

${ }^{64}$ SCHOPENHAUER, A. MVR I, § 15, p. 135-136.

${ }^{65}$ SCHOPENHAUER, A. N, p. 43.

${ }^{66}$ SCHOPENHAUER, A. MVR I, § 14, p. 115.

${ }^{67}$ SCHOPENHAUER, A. MVR II vol. 1, cap. 17, p. 272.

${ }^{68}$ SCHOPENHAUER, A. N, p. 23.

${ }^{69}$ SCHOPENHAUER, A. MVR II vol. 1, cap. 17, p. 272. 
dogmaticamente o desconhecido como explicação para o desconhecido, ou seja, idem per idem. Para Schopenhauer, a metafísica deve dar um passo além da mera consideração causal, entretanto, não pode ser um discurso vazio, sem significado e ignorante das descobertas científicas. As ciências empíricas que, por sua vez, "seguem seu próprio caminho sem uma tendência filosófica, são", para o filósofo, “como um rosto sem olhos." ${ }^{70}$. Em Schopenhauer, metafísica e ciência, portanto, se apoiam mutuamente. A metafísica necessita da ciência para que não transcenda o limite do conhecimento se apoiando em dogmas, como por exemplo, "o Absoluto, a substância absoluta, Deus, infinito, finito, identidade absoluta, ser, essência, entre outros", e a ciência necessita de uma metafísica que lhe forneça a chave de todos os seus $\operatorname{pressupostos}^{71}$.

Neste contexto, a fisiologia é responsável por sistematizar os conhecimentos sobre as atividades típicas do organismo que são obtidos por exploração controlada das mesmas e, consequentemente, é o contexto perfeito para a correção dos pressupostos metafísicos da ciência em geral e o estabelecimento de uma metafísica imanente. Por isso o estudo da fisiologia, primeiramente através de Blumenbach, é uma importante ponte para Schopenhauer chegar à metafísica do mundo ${ }^{72}$. Assim, enquanto a fisiologia é a

ciência da cega atividade da vontade no homem [...], nos permite conhecer todo o mecanismo interior a as funções graças as quais a vida existe e se conserva; ela descreve com precisão os vários processos e o modo segundo o qual se conectam uns aos outros e se favorecem reciprocamente ${ }^{73}$.

Em uma carta a Fruenstädt de 1852, Schopenhauer descreve a fisiologia como "o ponto culminante das ciências da natureza e ao mesmo tempo é sua área mais

\footnotetext{
${ }^{70}$ SCHOPENHAUER, A. MP III, 31, p. 82.

${ }^{71}$ SCHOPENHAUER, A. MVR II vol. 1, cap. 7, p. 144. A metafísica que se exclui do contato com a ciência, para Schopenhauer, "flutua no ar sem qualquer suporte, e não poderá nunca chegar a um resultado efetivo".

72 Para Schopenhauer, "o centro de expressão fenomênica da vontade é a trama dos gânglios no abdômen”, ou o Plexo Solar. O sistema nervoso e o sistema cerebral, articulam, na fisiologia humana, a dupla perspectiva schopenhaueriana sobre o mundo, isto é, vontade e representação. (SCHOPENHAUER, A. Metafisica della natura, p. 62) A vontade, que se expressa na matéria vivente é, a partir de uma perspectiva analógica, "o punctum saliens [ponto de saliência] do ovo cósmico", escreve Schopenhauer no capítulo sobre Anatomia Comparada, do texto Sobre a Vontade na Natureza (p. 89).

${ }^{73}$ SCHOPENHAUER, A. Metafisica della natura, p. 61.
} 
obscura"74. Na Metafísica da natureza nos diz que, "a força pela qual tudo é mantido em constante movimento, a fisiologia não pode ulteriormente explicá-la, essa ciência a chama força vital (Lebenskraft) e a razão a deixa como qualitas occulta. À Filosofia é reservada a tarefa de mostrar que a essência interior desta força é a vontade." ${ }^{75}$. Neste sentido, "todo impulso formativo, nisus formativus, vis plastica, é vontade cega." história natural blumenbachiana, com seu método de reflexão analógica para compreender as forças orgânicas, é o ponto de incidência da metafísica da natureza de Schopenhauer. A filosofia da Vontade é, portanto, a interpretação do fenômeno em geral por analogia com a expressão interna dos sucessivos atos de uma vontade cega, é " $a$ ciência da experiência em geral" ${ }^{\text {"77 }}$ que faz da experiência interna a chave para compreender metafisicamente a externa. É a decifração do "macrocosmo somente em função do microcosmo" ${ }^{, 78}$. Em sentido metafórico, é algo, por assim dizer, como uma fisiologia do mundo.

Em seu caderno de anotações às aulas de Blumenbach, Schopenhauer segue seu professor na compreensão de que a fisiologia foi a ciência com os maiores e mais significativos avanços, desenvolvimentos e profundas reflexões sobre a natureza no decorrer dos séculos ${ }^{79}$ e, conforme Marco Segala, "é importante não subestimar a afinidade entre a metodologia schopenhaueriana e aquela dos cientistas alemães conhecidos por ele. [...] A diferença entre ciência e metafísica era de outra espécie e envolveu um conteúdo diferente." ${ }^{\nexists 0}$. O próprio filósofo nos dá sinal disso na seguinte anotação de 1813:

A Filosofia tem uma grande semelhança com a anatomia do cérebro. Uma falsa filosofia, ou seja, uma visão equivocada do mundo, e uma anatomia errada do cérebro, dissecam e separam aquilo que está unido em um todo e como um só. [...] A verdadeira filosofia e a anatomia adequada do cérebro, dissecam e analisam tudo corretamente, descobrem e deixam como uno o que é uno, e somente separam e expõe as peças que são heterogêneas ${ }^{81}$.

\footnotetext{
${ }_{75}^{74}$ SCHOPENHAUER, A. Correspondance complète, p. 384.

${ }^{75}$ SCHOPENHAUER, A. Metafisica della natura, p. 61.

${ }^{76}$ SCHOPENHAUER, A. Metafisica della natura, p. 61.

${ }^{77}$ SCHOPENHAUER, A. MVR II vol. 1, cap. 17, p. 276.

${ }^{78}$ SCHOPENHAUER, A. MP III, 302, p. 664.

${ }^{79}$ STOLLBERG, J. und BÖKER, W. ," ... die Kunst zu sehn“ Arthur Schopenhauers Mitschriften der Vorlesungen Johann Friedrich Blumenbachs (1809-1811), p. 97.

${ }^{80}$ SEGALA, M. I fantasmi, Il cervello, L'anima: Schopenhauer, l'occulto e la scienza.. 49-50.

${ }^{81}$ SCHOPENHAUER, A. MP I, 84, p. 45 [1813]. 
Revista Voluntas: Estudos sobre Schopenhauer - Vol. 6, № 1 - $1^{\circ}$ semestre de 2015 - ISSN: 2179-3786 - pp. 44-84.

Então, se é necessário, por um lado distinguir entre o uso científico e o uso metafísico da analogia, não se pode por outro lado deixar de perceber que se trata do mesmo mecanismo de reflexão, ou seja, a distinção metodológica entre a ciência e a metafísica envolve, além da diferença do objeto de cada uma, a aplicação da causalidade e não exatamente a utilização da abordagem comparativa e a reflexão analógica $^{82}$.

\section{Sobre a analogia}

A analogia, desde tempos muito remotos, é um mistério, mas, principalmente, é uma ferramenta que desempenha muitas funções com resultados determinantes na construção e evolução da cultura de forma geral. Enquanto ferramenta basilar no desenvolvimento da racionalidade, a analogia desperta a atenção de um grande número de estudiosos das mais diversas áreas, sendo geralmente considerada como um princípio elementar do pensamento em todos os níveis de investigação e reflexão. O mecanismo de transferência de informações de um domínio ao outro numa relação de similaridade pode chamar atenção para alguns aspectos da realidade que de outro modo não poderíamos compreender. Assim, a analogia pode contribuir efetivamente na interpretação daquilo que permanece como ponto crítico e limite no conhecimento. A abordagem comparativa e a reflexão analógica, enquanto métodos de investigação e compreensão, possuem, portanto, uma aplicação vasta e emblemática ${ }^{83}$.

Na ciência, como vimos, "o uso da analogia, desde a antiguidade, tem sido uma característica distintiva do pensamento científico. O raciocínio analógico desempenha

\footnotetext{
${ }^{82}$ Cabe ressaltar também que a intensão aqui não é a de defender uma fusão entre o método científico e método filosófico, interditado pelo próprio filósofo, mas compreender o sentido dessa coincidência da analogia na ciência e na metafísica da Vontade.

${ }^{83} \mathrm{Na}$ filosofia antiga, por exemplo, a analogia é uma noção basilar em Platão, cuja cosmologia dividiu o mundo em ideias (arquétipos eternos, imóveis e imutáveis) e coisas sensíveis (cópias contingentes submetidas à corrupção temporal), estabelecendo entre o mundo inteligível e o mundo sensível uma relação de semelhança e participação. Assim, aquilo "que é copiado do arquétipo, por se tratar de uma cópia, estabelecem com essa cópia uma relação de verossimilhança e analogia" (PLATÃO, Timeu-Crítias, 29 a.C, p. 96). A analogia é o "supremo princípio da unidade do Bem" (RALF M. W. STAMMBERGER, On Analogy: An Essay Historical and Systematic, p. 13). Em Aristóteles, há uma analogia quando "o segundo termo está para o primeiro na igual relação em que está o quarto para o terceiro, porque neste caso, o quarto termo poderá substituir o segundo, e o segundo, o quarto.” (ARISTÓTELES, Poética, XXI, p. 261). A analogia é aqui vista metodologicamente como o princípio de uma relação proporcional em que a semelhança exerce um papel constitutivo. Paul Ricoeur explica que também o livro das Categorias é a introdução ao problema da analogia” (RICOEUR, P. A Metáfora Viva, p. 403). Como se pode perceber, o assunto do estatuto da analogia ocupou boa parte da preocupação metodológica tanto na ciência, quanto na filosofia de forma geral.
} 
muitos e importantes papéis na evolução da ciência. É uma poderosa ferramenta heurística que auxilia a formulação de novas teorias." ${ }^{\text {84 }}$. Joseph Priestley ${ }^{85}$, por exemplo, considerou que a "analogia é nosso melhor guia em todas as investigações filosóficas; e em todas as descobertas, que não foram feitas por mero acidente, foram feitas com o auxílio dela" ${ }^{86}$. John Herschel $^{87}$ defende que,

se a analogia de dois fenômenos é muito estreita e surpreendente, enquanto, ao mesmo tempo, a causa de um deles seja muito evidente, torna-se quase impossível recusar e admitir a ação de uma causa análoga no outro, embora, por si somente, não tão óbvia." ${ }^{18}$

Norman Campbell considera a analogia como um elemento intrinsecamente constitutivo das teorias e concebê-las de forma meramente acessória ou exterior ao raciocínio científico, "é tão absurdo quanto considerar a melodia como uma ajuda para a composição de sonatas." ${ }^{89}$. Esa Itkonen defende que todas as grandes descobertas da filosofia e da ciência são baseadas em analogias, e que podem ser invocados os seguintes nomes em apoio a esta afirmação: "Pitágoras, Platão, Aristóteles, Occam, Kepler, Descartes, Newton, Spinoza, Hobbes, Hume, Kant, Hegel, Darwin, Turing, Shannon; e outros podem ser facilmente adicionados." 90 . A fisiologia de Blumenbach e a metafísica de Schopenhauer constituem, a meu ver, excelentes exemplos do uso exuberante e significativo de analogias e, desse modo, ambos ocupariam um lugar importante na lista de Itkonen.

A analogia pode produzir um esquema exploratório eficiente em se tratando de

\footnotetext{
${ }^{84}$ BARTHA, P. By Parallel Reasoning: The Construction and Evaluation of Analogical Arguments, p. 2.

${ }^{85}$ Priestley, J.: The History and Present State of Electricity, p. 14.

${ }^{86}$ Embora não existam registros especificamente dessa obra no volume V dos Handschriftlichen Nachlaß editado e publicado por Arthur Hübscher que contém a bibliografia particular de Schopenhauer e também não na publicação de uma lista de livros emprestados da biblioteca de Weimar por Schopenhauer e publicada em Schopenhauer Jahrbuch 1923-1925, são notórias as referências elogiosas a outras duas obras importantes de Preistley intituladas Disquisitions relating to Matter and Spirit (1777), em SCHOPENHAUER, A. MVR I p. 619, e The Doctrine of Philosophical Necessity Illustrated (1777) em SCHOPENHAUER, A. MVR I, p. 374.

${ }^{87}$ John Frederick William Herschel (1792-1871) foi um matemático, químico e astrônomo inglês, fillho de William Herschel (1738 - 1822), astrônomo com quem Schopenhauer se encontrou ainda jovem durante a viagem com os pais. Schopenhauer citou elogiosamente, porém não sem críticas as obras $A$ Treatise on Astronomy (1833) e Outlines of Astronomy (1849) de John F. W. Herschel, entretanto, não conhecemos registros de que Schopenhauer consultou a obra supracitada intitulada: A Preliminary Discourse on the Study of Natural Philosophy (1830).

${ }^{88}$ HERSCHEL, J.: Preliminary Discourse On The Study Of Natural Philosophy, p. 149.

${ }^{89}$ CAMPBEL, N. Physics The Elements, p. 130.

${ }^{90}$ ITKONEN, E. Analogy as Structure and Process: Approaches in linguistics, cognitive psychology and philosophy of science. p. 11.

Metafísica e ciência: a vontade e a analogia em Schopenhauer 
relações estruturais de similaridade onde um dos termos da comparação é conhecido ou aceito e outro desconhecido. Neste sentido, o conceito e o mecanismo próprios da analogia se apresentam de muitos modos diferentes, contendo, no entanto, um traçado comum essencial. Segundo a definição lapidar de Paul Bartha,

Uma analogia é uma comparação entre dois objetos, ou sistema de objetos e destaca os aspectos em que são pensados como semelhantes. O raciocínio analógico é qualquer tipo de pensamento que dependa de uma analogia. Um argumento analógico é uma representação explícita de uma forma de raciocínio analógico que cita similaridades aceitas entre dois sistemas para apoiar uma conclusão de que alguma semelhança adicional existe ${ }^{91}$.

Se na reflexão analógica a transposição de significados de um domínio para outro concerne às relações de semelhança e similaridade, então, tais relações têm como característica essencial auxiliar, aprofundar e ampliar a compreensão que temos do domínio alvo, seja na ciência ou na filosofia.

Vosniadou e Ortony esclarecem que a capacidade de perceber as semelhanças e analogias é um dos aspectos mais fundamentais da racionalidade e que o raciocínio analógico envolve

\begin{abstract}
a transferência da informação relacional de um domínio que já existe na memória (geralmente referido como domínio fonte ou base) para um domínio a ser explicado (referido como domínio alvo). Similaridade está implicada neste processo, porque uma analogia útil e bem sucedida depende da existência de algum tipo de semelhança entre o domínio fonte e o domínio alvo e porque a percepção de semelhança poderá desempenhar um papel importante em alguns dos processos-chaves associados com o raciocínio analógico ${ }^{92}$.
\end{abstract}

Neste sentido, a analogia é crucial, pois está relacionado com a compreensão de que a racionalidade "nem sempre funciona com base em regras de inferência gerais de conteúdo livre, mas, ao contrário, é muitas vezes ligada a entidades particulares de conhecimento e é fortemente influenciado pelo contexto em que ela ocorre." 93.

\title{
6. O estatuto da analogia em Schopenhauer
}

\footnotetext{
${ }^{91}$ BARTHA, P. By Parallel Reasoning: The Construction and Evaluation of Analogical Arguments, p. 1.

${ }^{92}$ VOSNIADOU and ORTONY, Similarity and Analogical Reasoning, p. 6-7.

${ }^{93}$ VOSNIADOU and ORTONY, Similarity and Analogical Reasoning, p. 1. 
Chama a atenção o fato de que apesar de uma analogia ocupar o cerne de sua filosofia, Schopenhauer não se delongou em uma análise direta do método analógico, apenas indiretamente é possível extrair as consequências mais importantes do assunto. Paradoxalmente, sua filosofia invoca analogias de vários tipos e com finalidades distintas em muitos casos, sendo o principal deles, a analogia entre micro e macrocosmo, isto é, entre o corpo conhecido como vontade e o mundo. A analogia é o mecanismo metodologicamente apropriado para solucionar o problema do mistério do mundo, já que nas relações de similaridade, partimos de um domínio fonte conhecido para transferir uma informação chave a um domínio alvo pouco conhecido, a saber, as qualidades ocultas da matéria. O filósofo concebe o valor epistemológico da similaridade envolvida no argumento por analogia do seguinte modo:

As similitudes (Gleichniss) são de grande valor na medida em que reduzem uma relação desconhecida a outra conhecida. ${ }^{94}$ Também as metáforas mais detalhadas que chegam até a parábola (Parabel) ou a alegoria (Allegorie) são uma simples redução de alguma relação à sua representação mais simples, intuitiva e palpável. Inclusive a construção dos conceitos se baseia no fundo em metáforas, uma vez que resultam da captação do semelhante e a eliminação do diferente nas coisas. Além disso, toda compreensão autêntica consiste em último termo em uma captação de relações (un saisir de rapports), mas cada relação se captará com maior claridade e pureza quando a reconhecemos como idêntica em cursos muito diferentes e entre coisas totalmente heterogêneas. Com efeito, quando eu conheço uma relação como existente em um só caso isolado, terei dela um conhecimento meramente individual, a saber, unicamente intuitivo. Mas assim que eu capto a mesma relação em dois casos diferentes, possuo um conceito de toda a classe dessa relação e, portanto, um conhecimento mais profundo e completo. Precisamente porque as metáforas são uma alavanca potente para o conhecimento, a apresentação de metáforas surpreendentes e bem sucedidas dá testemunho de um entendimento profundo ${ }^{95}$.

\footnotetext{
${ }^{94}$ SCHOPENHAUER, A. P II, cap. 23, § 289, p. 561-562; MP I, 484, p.356; MP I, 514, p. 380; MP III,71, p. 185; MP III, 89, p. 190; MP IV, 51, p. 35.

${ }_{95}$ P II, cap. 23, § 289, p. 561-562. Schopenhauer, nas linhas que se seguem à passagem destacada aqui, cita a Poética e a Retórica de Aristóteles, optando por traduzir o termo $\mu \varepsilon \tau \alpha \varphi \rho \rho \alpha ́$ do grego para o alemão Gleichniss. Observe-se a questão envolvendo as palavras Gleichniss, Parabel e Allegorie. Gleichniss é traduzível para o português pelo termo parábola, por exemplo, se diz, como nos informa Rubens Torres Filho, "as Gleichnisse do Novo Testamento" (1987, p. 125). Entretanto, só se têm uma Gleichniss quando se compara duas coisas ou se reconhece uma relação de semelhança, enquanto o termo Parabel, que também é tradutível pelo termo parábola ou alegoria, é uma história curta, geralmente de cunho religioso, que transporta certos princípios morais e ou éticos que são justapostos a um plano de apreensão mais compreensível. Allegorie, que é traduzível para o português por alegoria se caracteriza por uma "referência ao outro, esse sentido que se esgota na relação" (FILHO 1987, p. 126). Há ainda a palavra alemã Metapher que deriva do grego $\mu \varepsilon \tau \alpha \varphi \rho \rho \alpha ́$ que é traduzível por metáfora e compreendido como um tropo ou figura de linguagem poética ou retórica descrita por Aristóteles conforme vimos mais à cima. Na 
Neste sentido, a similaridade estrutural básica da realidade empírica é fundamental para Schopenhauer, pois, tanto no trabalho da ciência quanto no discurso metafísico, é ela que permite a comparação entre fenômenos que se assemelham em algum grau. No âmbito causal científico a similaridade nos permite visualizar as semelhanças de família entre os produtos da natureza no que concerne às suas formas e funcionamentos. Ou seja, se para Schopenhauer "o conhecimento do idêntico em fenômenos diferentes, e do diferente em fenômenos semelhantes, é justamente, como Platão amiúde observa, a condição da filosofia"96, poderíamos concluir que a analogia é a única que, em certo sentido, "não nos abandona no fenômeno, mas, através dele, levanos à COISA-EM-SI" ${ }^{\prime 97}$.

$\mathrm{Na}$ ciência, os conhecimentos são obtidos pela abordagem comparativa e sistematizados para facilitar nosso saber sobre o mundo criando a ocasião e as condições necessárias para que o problema da metafísica apareça corrigido e claramente exposto $^{98}$. Na metafísica, a similaridade é o que permite um argumento de analogia capaz de nos conduzir, quando dotado da chave correta, a um discurso significativo sobre a coisa-em-si, atribuindo à experiência em geral um sentido metafísico.

Assim, estrategicamente, a analogia é o melhor caminho para o conhecimento

tradução italiana do texto de Schopenhauer editada por Mario Carpitella, optou-se por traduzir Gleichniss por similitudini, similitude ou similaridade em vez de metáfora. Essa também foi a opção de E. F. J. Payne para a tradução em inglês. Pilar López de Santa Maria optou por traduzir Gleichniss para o espanhol metáfora, provavelmente por guardar a referência de Schopenhauer a Aristóteles. Schopenhauer refletiu sobre a questão das Gleichnisse também em outras passagens importantes das quais destacamos a seguinte: "a relação entre a vontade e a representação não se ajusta ao princípio de razão. Por isso somente pode ser qualificada de relação em sentido metafórico (metaphorisch)." (SCHOPENHAUER, A MP I, 347-348 (521) <1816>). Matthias Kossler (KOSSLER, M. A vida é apenas um espelho - o conceito crítico de vida de Schopenhauer, p. 26) nos faz perceber que na mesma passagem da primeira edição de O Mundo em 1819 Schopenhauer muda o termo metaphorisch por gleichnißweise." (Schopenhauer, A. Die Welt als Wille und Vorstellung. Faksimiledruck der ersten Auflage von 1819 [1818]. Frankfurt /M 1987, S. 692.) Posteriormente, na segunda edição da mesma obra em 1844, Schopenhauer retira a passagem inteira, o que indica a preocupação do filósofo com complexidade da questão. Neste sentido, a tradução mais adequada nos parece ser Gleichniss por Simile ou Similitude, já que, segundo nossa compreensão atual do problema, isto está mais próximo da ideia de "espelhamento" que Schopenhauer introduz como característica de sua filosofia. (SCHOPENHAUER, A. MVR §15, p. 137-138).

${ }^{96}$ SCHOPENHAUER, A. MVR I, § 22, p. 169-170.

${ }^{97}$ SCHOPENHAUER, A. MVR I, § 21, p. 168.

${ }^{98}$ Cabe lembrar que, para Schopenhauer, o problema da metafísica é dado empiricamente, ou seja, é uma teoria do conteúdo geral da consciência ou "a ciência da experiência em geral" e, nesse sentido, deve se constituir como um saber extraído da própria experiência. Contudo, não se deve perder de vista que, segundo o filósofo, "a fonte cognitiva da metafísica não é somente a experiência externa, mas também a interna; [...] e faz desta a chave daquela" (SCHOPENHAUER, A. MVR II vol. 1, cap. 17, p. 276). A ciência, enquanto saber sistematizado, quando corrigido e ampliado com novas descobertas, expõe com maior precisão o problema da metafísica, isto é, corrige e facilita o conhecimento conduzindo-o até àquilo que será o objeto da metafísica. 
em geral, a nossa melhor maneira para tomar de assalto o "castelo" do conhecimento do mundo 99 . Em suma, a analogia é precisamente aquela "passagem subterrânea" ou "conexão secreta"100, pela qual o discurso sobre a coisa-em-si se torna possível já que estabelece uma conexão de sentido entre os distintos planos da vontade e da representação na obra de Schopenhauer.

É interessante notar que, enquanto o método analógico é vantajoso para a compreensão da natureza na ciência, já que a razão não pode conhecer às coisas-em-simesmas, na filosofia de Schopenhauer a analogia tem o poder de limitar o discurso metafísico à imanência do mundo, mostrando, pelas suas características próprias, as limitações da metafísica e do discurso sobre a coisa-em-si. Ou seja, para Schopenhauer, o único discurso possivel sobre a coisa-em-si se constrói por analogia, isto é, nos termos de uma atividade fisiológica diretamente conhecida no sentido interno, imediatamente iluminada pela consciência e elevada ao conhecimento abstrato por reflexão continuada.

Portanto, nos parece que Schopenhauer, ao evocar uma analogia no cerne de sua reflexão, o faz de forma consciente, trata-se de uma estratégica que visa compreender a experiência em termos conhecidos e limitar o discurso metafísico mantendo-o em constante conexão com a experiência e com a visão científica de sua época. Trata-se de uma imposição de limites ao discurso sobre a coisa-em-si e não um suposto conhecimento direto de tal coisa. Neste sentido é importante discernir que, apesar de tais poderes atribuídos à analogia, Schopenhauer estava ciente quanto aos seus limites na filosofia da natureza.

Segundo o filósofo, a "caça por analogias" ${ }^{101}$, semelhanças e contrates na natureza é certamente interessante e útil, entretanto "nunca constitui uma filosofia." 102 A "verdadeira filosofia", em termos schopenhauerianos, deve, além da análise comparativa e da reflexão analógica, partir da experiência e encontrar em terra firma uma informação que seja a chave de interpretação daquilo que o mundo é de acordo com sua realidade mais íntima. Por isso, a filosofia verdadeira deve se harmonizar com a consideração científica da natureza, ou seja, ser imanente, abdicando de qualquer

\footnotetext{
${ }^{99}$ SCHOPENHAUER, A. MVR I, § 17, p. 156.

${ }^{100}$ SCHOPENHAUER, A. MVR II vol. 1, cap. 18, p. 299.

${ }^{101}$ SCHOPENHAUER, A. MVR I $§ 27$, p. 207.

102 SCHOPENHAUER, A. MP I, 542, p. 399. 
transcendência. ${ }^{103} \mathrm{Ou}$ seja, sozinha a analogia nunca pode constituir uma filosofia verdadeira, pois o domínio fonte da transferência analógica pode ser tão, ou mais, desconhecido quanto o domínio alvo, e então, se pretenderá, segundo Schopenhauer, equivocadamente decifrar o enigma por meio de algo ainda mais enigmático como os conceitos abstratos da metafísica transcendente.

O que fornece apoio à compreensão do mundo em termos de essência e coisaem-si imanente é a transferência analógica da informação oferecida pelo corpo e seus estados psíquicos e fisiológicos, isto é, da vontade entendida como uma chave interpretativa, para a reflexão sobre a totalidade dos fenômenos. $\mathrm{Na}$ direção inversa, o que garante um grau de plausibilidade para a transferência analógica compreendida como mecanismo de reflexão é o grau de segurança epistêmica do autoconhecimento do corpo na experiência interior, ou seja, o conhecimento cristalino e imediato do domínio fonte, a saber, da vontade compreendida como fundamento dos estados, atividades fisiológicas e ações do corpo, que lhe dá o status de "verdade filosófica". ${ }^{104} \mathrm{O}$ corpo identificado com a vontade, em Schopenhauer, fornece um grau de suporte epistêmico para interpretar o mundo no mesmo termo. Esse procedimento tem por objetivo incrementar a compreensão que se tem do domínio alvo, isto é, do mundo, na medida em que elabora uma metáfora conceitual para ele.

Schopenhauer estava consciente do aspecto heurístico envolvendo a reflexão por analogia, ${ }^{105}$ apesar disso, construiu para a metafísica um sentido no qual a analogia decifra o enigma do mundo. Entretanto, Schopenhauer, faz a ressalva de que a filosofia não é um saber plenamente acabado e a analogia fornece uma compreensão relativa, ou indireta do domínio que se quer conhecer, ou seja, "não importa a tocha que possamos

\footnotetext{
${ }^{103}$ Schopenhauer questiona: "Não parece antes diretamente contrário à verdade que para decifrar o enigma da experiência, a saber, do único mundo que há ante nós, tenha-se que prescindir totalmente dele [...]? Não é mais apropriado pensar que a ciência da experiência em geral e como tal se extraia também da experiência? Não é absurdo que quem fala da natureza das coisas não tenha que contemplar as coisas mesmas, mas sim, somente ater-se a certos conceitos abstratos? (SCHOPENHAUER, A. MVR II vol. 1, cap. 17, p. 277.

${ }^{104}$ SCHOPENHAUER, A. MVR I $\S 18$, p. 160.

${ }^{105}$ Para compreender o estatuto da analogia em Schopenhauer cabe lembrar Kant para quem a coisa-em-si está absolutamente fechada à razão. A analogia possui, segundo Kant, um valor epistemológico regulativo nas relações qualitativas, ou seja, na filosofia, "a analogia não é a igualdade de duas relações quantitativas, mas de relações qualitativas, nas quais, dados três membros, apenas posso conhecer e dar $a$ priori a relação com um quarto, mas não esse próprio quarto membro; tenho, sim, uma regra para o procurar na experiência e um sinal para aí o encontrar. Uma analogia da experiência será pois apenas uma regra, segundo a qual a unidade da experiência (não como a própria percepção, enquanto intuição empírica em geral) deverá resultar das percepções e que, enquanto princípio a aplicar aos objetos (aos fenômenos), terá um valor meramente regulativo, não constitutivo". (KANT, I. Crítica da razão pura. A179-180/B222.)
} 
acender, e o tamanho do quarto que ela possa iluminar, o nosso horizonte estará sempre rodeado pela profundidade da noite" ${ }^{\text {106 }}$. A metafísica, em Schopenhauer é a interpretação do mundo em termos daquilo que nele se apresenta de forma mais nítida e intimamente conhecida, mas isso não é uma solução absolutamente definitiva para a questão. Schopenhauer, ao contrário, parte da ideia de que "uma solução efetiva e positiva para o enigma do mundo deve ser algo que o intelecto humano é inteiramente incapaz de entender e conceber, $[\ldots]^{\prime 107}$.

Assim, Schopenhauer parece estar ciente quanto ao valor regulativo da analogia na metafísica da natureza. Entretanto, a verdadeira filosofia, aquela que decodifica a experiência, deve partir do conhecimento imediato e da contemplação das ideias, isto é, de um domínio fonte que garanta alguma plausibilidade e eficiência da transferência na relação analógica. Ou seja, quando se descobre "a chave para um enigma, a sua verdade se demonstra no fato de que todas as suas formulações estão de acordo com ela" e, assim, nos diz Schopenhauer, "minha teoria permite ver harmonia e coerência no contrastante emaranhado de fenômenos deste mundo, e resolve as muitas contradições que este apresenta, desde que os contempla de outra perspectiva" ${ }^{\prime 108}$.

Schopenhauer, no entanto, se distancia da filosofia crítica de Kant não exatamente na compreensão do valor regulativo da analogia como procedimento de investigação, mas quanto ao aspecto epistemológico da experiência interna e o sentido do conceito de vontade. Segundo a perspectiva proposta aqui, Schopenhauer encontra o valor regulativo da analogia nas aulas de fisiologia e anatomia comparada de Blumenbach a partir de 1809 e confirma isso em Kant. No entanto, as ciências ensinadas por Blumenbach acrescentam a Schopenhauer a compreensão de que o corpo e seus estados fisiológicos conduzem a reflexão até os confins da natureza onde a metafísica inicia seu trabalho. A fisiologia e a anatomia comparada ensinadas por Blumenbach são cruciais para a compreensão de Schopenhauer de que o corpo e seus impulsos, suas atividades psíquicas e fisiológicas, transformações e ações são o ponto de articulação entre a metafísica e a ciência, da experiência interna com a externa. $\mathrm{O}$ corpo, portanto, é o locus metaphisycum em Schopenhauer e, neste sentido, deve ser o domínio fonte da relação analógica, isto é, o microcosmo capaz de dar um significado às

\footnotetext{
${ }^{106}$ SCHOPENHAUER, A. MVR II vol. 1, cap. 17, p. 282.

${ }^{107}$ SCHOPENHAUER, A. MVR II vol. 1, cap. 17, p. 282.

${ }^{108}$ SCHOPENHAUER, A. MVR II vol. 1, cap. 17, p. 282.

Metafísica e ciência: a vontade e a analogia em Schopenhauer
} 
inúmeras analogias entre os produtos da natureza, ou seja, ao domínio alvo, o macrocosmo. O discurso sobre a coisa-em-si é modificado em relação a Kant quando Schopenhauer defende que, embora incognoscível, devemos compreender um discurso sobre a coisa-em-si unicamente nos termos de uma manifestação mais cristalina, a saber, a vontade como o significado vivo das atividades do corpo.

A resposta para a questão sobre o enigma da experiência em geral, portanto, envolve o status epistemológico de "verdade filosófica"109 atribuído à descoberta da vontade como fundamento das ações do corpo, ou melhor, da identidade do sujeito volente com o sujeito cognoscente na vida do organismo, ou o nó do mundo ${ }^{110}$. O sujeito “[...] se enraíza neste mundo, encontra-se nele como INDIVÍDUO, isto é, seu conhecimento, [...] é no todo, intermediado por um corpo, cujas afecções, como se mostrou, são para o entendimento o ponto de partida da intuição do mundo" ${ }^{111}$. Na experiência interna, segundo o filósofo, nos aparece, então, "o conhecido completa e exclusivamente como vontade"112. Esta, "e tão-somente esta, fornece-lhe a chave para o seu próprio fenômeno, manifesta-lhe a significação, mostra-lhe a engrenagem interior de seu ser, de seu agir, de seus movimentos"113.

A analogia é a ferramenta constitutiva do sistema teórico organizado de Schopenhauer e o que faz desse sistema uma filosofia é a descoberta da vontade, enquanto verdade filosófica, como domínio fonte da relação analógica. O corpo aparece como ponto central para o qual convergem a representação e a vontade, ou seja, é o

\footnotetext{
${ }^{109}$ SCHOPENHAUER, A. MVR I $\S 18$, p. 160.

${ }^{110}$ SCHOPENHAUER, A. PR, § 42, p. 206.

${ }^{111}$ SCHOPENHAUER, A. MVR I $\S 18$, p.156. O papel do corpo, e das funções fisiológicas deste, na filosofia de Schopenhauer é nuclear, pois é a partir dele que uma interpretação do mundo se faz possível em termos de essência e coisa-em-si. O corpo do sujeito é de natureza peculiar e um ponto decisivo para a reflexão filosófica. O corpo, enquanto classe de objetos para o sujeito, não compreende mais que um só objeto para cada indivíduo, a saber, o objeto imediato do sentido interno (SCHOPENHAUER, A. PR. cap. IV, §22, p.133), o sujeito da volição, que é objeto para o sujeito cognoscente que, em verdade, se dá unicamente no sentido interno e, por isso, aparece somente no tempo, não no espaço, e aqui também com uma considerável limitação. (SCHOPENHAUER, A. PR, cap. VII, § 40, p.202) O corpo, como objeto imediato da reflexão filosófica e "intermediário para a intuição de todos os demais objetos" (SCHOPENHAUER, A. PR. Cap. IV, § 22, p. 132-133), se torna o ponto de decifração da experiência em sua totalidade.

${ }^{112}$ SCHOPENHAUER, A. PR cap. VII, § 41, p. 202.

${ }^{113}$ SCHOPENHAUER, A. MVR I $\S 18$, p. 156-157. É importante ressaltar aqui que o conhecido no sentido interno não é uma entidade, mas a vivência íntima de uma atividade. O conhecimento que temos da nossa própria vontade não se separa do nosso corpo. (SCHOPENHAUER, A. MVR I, § 18, p. 159). O conhecimento que cada um tem de si "não é nem uma intuição (pois toda intuição é espacial), nem é vazio; pelo contrário, é mais real do que qualquer outro conhecimento. Além disso, não é a priori, como todo conhecimento meramente formal, mas inteiramente a posteriori." (SCHOPENHAUER, A. MVR II vol. 1, cap. 18, p. 299) O autoconhecimento, segundo Schopenhauer, também não ocorre por meio de deduções, pois é de natureza indemonstrável, ou seja, por não possuirmos nenhum outro conhecimento mais imediato ou anterior a este, não se pode extraí-lo dedutivamente de nenhum fundamento anterior.
} 
ponto de perspectiva no qual a metafísica da Vontade se articula com a ciência e, desse modo, se torna um discurso imanente sobre a coisa-em-si ${ }^{114}$. Enquanto elemento metodológico comum em Schopenhauer e na ciência, a analogia aparece como uma herança do contato do primeiro com esta última e com as especulações fillosóficas sobre a natureza que se praticava em Göttingen ${ }^{115}$. O próprio filósofo menciona vários cientistas e ressalta os bem sucedidos exemplos de filosofia da zoologia, por um aspecto interessante no contexto dessa pesquisa, a saber, "pois todos expuseram claramente a analogia universal, o relacionamento interno, o tipo permanente e a conexão sistemática das formas animais"

\section{Sobre a interpretação da tese analógica de Schopenhauer}

A analogia é, por um lado, uma ferramenta extremamente útil na produção do conhecimento, entretanto, vimos também que, por outro lado, alguns problemas foram atribuídos à abordagem comparativa e a reflexão analógica como suas limitações essências. Entre os principais problemas podem ser citados a ausência de um critério de avaliação sedimentado em uma epistemologia da confirmação e justificação filosóficas para o procedimento racional da analogia e a impossibilidade lógica deste fornecer um

\footnotetext{
${ }^{114}$ Aqui se apoia uma suposta correção de Schopenhauer à Kant no que diz respeito à possibilidade do discurso sobre a coisa-em-si. Para o primeiro, uma realidade que não fosse representação ou vontade, mas um objeto em si "(como a coisa-em-si de Kant, que infelizmente degenerou em suas mãos), é uma nãocoisa fantasmagórica, cuja aceitação é um fogo fátuo da filosofia" (SCHOPENHAUER, A. MVR I, § 1, p. 45).

${ }^{115}$ Segundo Arthur Hübscher, o argumento de analogia nasce em 1814 em Dresden e faz parte da reunião das especulações provenientes do romantismo e do misticismo alemães sobre o valor da arte na decifração do mistério do mundo, isto é, da unidade do micro com o macrocosmo (HÜBSCHER 1989, cap. II, p. 70). Nossa hipótese não desconhece a tese de Hubscher, apena acrescenta que as ciências naturais estudadas pelo filósofo na faculdade de medicina de Göttingen, em especial a fisiologia e anatomia comparada de Blumenbach, forneceram um reforço empírico, ou um grau de plausibilidade, para a analogia entre o corpo e o mundo, na medida que o conhecimento empírico sobre o organismo e seus impulsos (Trieb) e atividades internas são o melhor modelo que possuímos para decifrar o enigma da unidade do homem com a natureza. A concepção schopenhaueriana do valor epistemológico da analogia é elaborada em meio a uma tensão entre as especulações do romantismo místico, Kant e as ciências. Enquanto no romantismo mistico a analogia é um princípio constitutivo da relação entre o homem e a natureza, em Kant é um princípio regulativo para investigação da experiência, e na ciência é uma ferramenta metodológica para a compreensão dos fenômenos, em Schopenhauer, quando o domínio fonte da relação analógica é conhecido (corpo-vontade) com um grau a mais de apoio epistêmico (verdade filosófica), a analogia se torna um modelo eficiente de interpretação, ou seja, "é o princípio fundamental de uma nova compreensão do mundo." (HÜBSCHER, A. The philosophy of Schopenhauer in its intellectual context: Thinker against the tide, p. 71). Falta, porém, precisar o sentido e o papel que a analogia desempenha na Metafísica da Vontade e em que medida isso coincide com aspectos metodológicos gerais das ciências naturais estudadas por Schopenhauer.

${ }^{116}$ SCHOPENHAUER, A. MVR II vol. 1, cap. 12, p. 206.

Metafísica e ciência: a vontade e a analogia em Schopenhauer 
Revista Voluntas: Estudos sobre Schopenhauer - Vol. 6, No 1 - $1^{\circ}$ semestre de 2015 - ISSN: 2179-3786 - pp. 44-84.

conhecimento direto do domínio alvo. Na mesma medida em que a analogia foi amplamente utilizada na produção do conhecimento científico e na reflexão filosófica, muitos problemas de ordem epistemológica, lógica, conceitual e metodológica foram exaustivamente desenvolvidos dentro de uma visão cética no que concerne ao uso desse recurso.

Em Schopenhauer, a analogia tem como objetivo principal discursar sobre a unidade e identidade do princípio que subjaz nas na multiplicidade das coisas comparadas. Com tais pretensões Schopenhauer não pode evitar a abordagem crítica de sua filosofia e muitas questões sobre as limitações e os resultados das suas analogias foram debatidas. Na obra Tratado de argumentação: a nova retórica (1996) de Perelman e Olbrechts-Tyteca lemos que a analogia é uma ferramenta instável de reflexão e argumentação,

\begin{abstract}
porque quem lhe rejeita tenderá a afirmar que não há "sequer analogia" e minimizará o valor do enunciado reduzindo-o a uma vaga comparação ou a uma aproximação puramente verbal. Mas quem invoca uma analogia tenderá, quase invariavelmente, a afirmar que há mais do que uma simples analogia. Esta fica assim entalada entre duas rejeições, a de seus adversários e a de seus partidários ${ }^{117}$.
\end{abstract}

A busca por uma superação da analogia foi, de fato, muitas vezes perseguida, com diferentes estratégias. Perelman e Olbrechts-Tyteca citam o próprio Schopenhauer como exemplo por se esforçar em "mostrar que tema e foro dependem de um princípio comum." ${ }^{118}$. De acordo com isso, o discurso sobre a unidade metafísica da Vontade como coisa-em-si seria uma maneira de superar a analogia que, no plano da representação, havia apenas explicitado o que, no plano metafísico, estava previamente posto como indiferenciado antes de qualquer reflexão por analogia. Isto têm algum apoio textual em Schopenhauer quando este diz que, todo o parentesco entre os diversos fenômenos da natureza "é mais do que uma simples analogia (Gleichniss): já é a identidade da coisa, da Vontade, nos graus muito diversos de sua objetivação, conforme os quais, a mesma lei do movimento se apresenta de modo distinto" ${ }^{119}$. Ou seja, para Perelman e Olbrechts-Tyteca, existem filosofias que concebem a analogia como

\footnotetext{
${ }^{117}$ PERELMAN e OLBRECHTS-TYTECA, Tratado da Argumentação: A Nova Retórica, p. 447.

118 PERELMAN e OLBRECHTS-TYTECA, Tratado da Argumentação: A Nova Retórica, p. 448.

${ }^{119}$ SCHOPENHAUER, A. P II, cap. 26, 307, p. 596.
} 
explicitação daquilo que está incluído no conjunto não diferenciado que a precede"120.

John E. Atwell também discute a questão negando a existência de uma analogia na argumentação de Schopenhauer. O intérprete argumenta que "na transferência do autoconhecimento para o mundo, a compreensão não ocorre por meio de um argumento de analogia." em verdade, o ser humano não tem outro modo disponível para conhecer qualquer coisa que seja, "simplesmente não há alternativa - exceto, claro, deixá-lo (mundo) absolutamente desconhecido ou relegá-lo a uma mera representação."121 Atwell, encontrou, portanto, um abono textual em Schopenhauer e sua interpretação do problema pode estar fundamentada na seguinte passagem:

não podemos encontrar em nenhuma parte realidade outra para atribuir ao mundo dos corpos. Assim, se este ainda deve ser algo mais que mera representação, temos de dizer que, exceto a representação, portanto em si e conforme sua essência intima, ele é aquilo que encontramos imediatamente em nós como vontade. Digo, "conforme sua essência mais intima." $" 122$.

Marcos Silva lista os seguintes pontos frágeis do argumento analógico de Schopenhauer:

(i) a invalidade lógica; (ii) a falta de critério para o alcance da extensão; (iii) a indeterminação do que está sendo realmente extendido; (iv) o caráter irrestrito da extensão analógica; (v) a natureza indireta do argumento (para evitar o solipsismo); e (vi) o colapso do que está sendo extendido. Assim tento apontar por que, apesar destes pontos frágeis, este argumento por analogia parece não ser de forma alguma problemático para Schopenhauer ${ }^{123}$.

Muitos outros problemas podem se somar na lista de Silva, por exemplo, a ausência de um parâmetro sólido para avaliação da eficiência e grau de adesão que um argumento analógico pode alcançar e sua justificação filosófica junto a uma epistemologia da confirmação. Silva conclui que, apesar do "raciocínio paradoxal, inválido, da retórica inflamada" e insuficiente do filósofo, é preciso perceber que

\footnotetext{
${ }^{120}$ PERELMAN, C. e OLBRECHTS-TYTECA, Tratado da Argumentação: A Nova Retórica, p. 451.

${ }^{121}$ ATWELL, J. Schopenhauer on the character of the world: the metaphysics of will, p. 102.

122 SCHOPENHAUER, A. MVR I $§ 19$, p. 163.

${ }^{123}$ SILVA, M.: On analogical arguments: Organizing logical and conceptual problems in sections 18 and 19 of Schopenhauer's The World as Will and Representation. In: Revista Voluntas: estudos sobre Schopenhauer $-2^{\circ}$ semestre $2011-$ vol. $2-\mathrm{n}^{\mathrm{o}} 2-\mathrm{p} .185$. 
"Schopenhauer tem uma filosofia de limites: limites de pensamentos, conhecimento e expressão, de experiências externas e internas" ${ }^{\text {124 }}$. Nos parece, então, que as analogias e as metáforas são recursos capazes de tornar a obra de Schopenhauer o sinal de uma mudança radical no modo tradicional de nos portarmos diante da existência e de discursarmos sobre algo existente independentemente das condições transcendentais do conhecimento. Portanto, em consideração ao fato de que Schopenhauer concebe a filosofia como reunião da ciência com a arte, uma avaliação meramente lógica corre o risco de reduzir a exuberância do pensamento a certas regras inferenciais circunscritas, ou seja, os critérios estritamente lógicos não são os únicos com suficiência para compreender Schopenhauer.

Giuseppe Invernizzi, neste caminho, acentua um papel determinante da analogia para o discurso sobre a Vontade, isto é, para denominação metafórica da coisa-em-si e, neste sentido, considerou as características destacadas da metafísica schopenhaueriana. “Já no primeiro volume do Mundo”, observa Invernizzi,

no qual fala sem hesitação da Vontade como "essência do nosso corpo", Schopenhauer mostra certa cautela ao empregar o termo "vontade" para indicar a essência de toda a realidade, a coisa em si, no seu significado mais geral. É neste contexto que vem usada a frequentemente citada fórmula denominatio a potiori, para enfatizar que se trata de uma extensão analógica ${ }^{125}$ a toda a realidade de um conhecimento que vale em próprio somente para o homem." ${ }^{126}$.

O próprio filósofo se esclarece sobre a relação entre a analogia e a tese da Vontade como coisa-em-si do seguinte modo:

\footnotetext{
${ }^{124}$ SILVA, M. On analogical arguments: Organizing logical and conceptual problems in sections 18 and 19 of Schopenhauer's The World as Will and Representation. In: Revista Voluntas: estudos sobre Schopenhauer $-2^{\circ}$ semestre $2011-$ vol. $2-\mathrm{n}^{\circ} 2-$ p. 213.

${ }^{125} \mathrm{~A}$ analogia entre coisas imediatamente semelhantes, por exemplo, corpos humanos entre si, denominase comparação literal. Na medida em que as semelhanças entre as coisas comparadas diminui, aumenta-se o grau figurativo, metafórico do processo analógico. Na denominação a potiori da Vontade como coisaem-si, o grau metafórico atinge o máximo de expressividade e figuração, de modo que se deve compreender tal denominação como uma imagem abstrata ou conceitual, do mundo. O conceito de vontade ganhar a mais ousada extensão recomendada pelo autor como imprescindível para a interpretação do fundamental de sua filosofia. Schopenhauer esclarece a questão e recomenda aos seus intérpretes: "estaria sempre numa renovada incompreensão quem não fosse capaz de levar a bom termo a aqui exigida ampliação do conceito de VONTADE, entendendo por esta palavra tão-somente a espécie designada até agora pelo termo [...]. Doravante, temos de separar de maneira pura em nosso pensamento a essência mais íntima, imediatamente conhecida desse fenômeno, e em seguida transmiti-la a todos os fenômenos mais débeis, menos nítidos da mesma essência, pelo que consumaremos a pretendida ampliação do conceito de vontade" (SCHOPENHAUER, A. MVR I § 22, p. 170).

${ }^{126}$ INVERNIZZI, G. Il Problema della cosa in sé e la concezione della Metafisica nella filosofia de Schopenhauer, p. 102.
} 
Assim como o conhecimento da unidade da Vontade como coisa-em-si em meio à infinita diversidade e variedade dos fenômenos é o único que nos fornece o verdadeiro esclarecimento sobre aquela analogia impressionante e inquestionável entre todas as produções da natureza, sobre aquela semelhança de família, que nos permite considerar a estas como variações do mesmo tema não dado; assim também em igual medida, mediante o conhecimento distinto e profundamente apreendido da harmonia e conexão essencial de todas as partes do mundo, da necessidade de sua gradação que acabamos de considerar, abre-se para nós uma verdadeira e suficiente intelecção da essência intima e significação da FINALIDADE inegável de todos os produtos orgânicos da natureza, finalidade que até pressupomos a priori quando consideramos e julgamos todos esses produtos.[... $]^{127}$

Portanto, não nos parece uma fácil negar a existência de uma analogia em Schopenhauer, o filósofo, em verdade, necessita dela para alcançar uma compreensão conceitual do nexus metafísicum da multiplicidade e da contradição em que se encontram os fenômenos naturais. Neste sentido, a unidade metafísica da vontade visa dar significado à analogia e não superá-la no sentido de negá-la. Ou seja, se a analogia, como vimos, está enraizada na própria estrutura da racionalidade ou na "conduta da inteligência" 128 , então ela jamais é plenamente superada e, em Schopenhauer, apenas carece de uma significação metafísica que será fornecida pela tese da Vontade como o uno no múltiplo.

\section{Considerações finais}

\footnotetext{
${ }^{127}$ SCHOPENHAUER, A. MVR I, 28, p. 219-220. Schopenhauer explica o sentido de sua tese: "A Vontade como coisa-em-si é inteira e indivisa em cada ser, assim como o centro é uma parte integrante de cada raio da circunferência. Enquanto o fim periférico desse raio está revolução mais rápida com a superfície que representa o tempo e o seu conteúdo, a outra extremidade, no centro, onde se encontra a eternidade, permanece em profunda paz, porque o centro é o ponto cuja metade ascendente não se distingue da descendente. [...] Aqui, é claro, caímos na linguagem mística e figurada (Bildersprache), mas esta é a única linguagem na qual alguma coisa pode ser dita sobre esse tema inteiramente transcendente. Do mesmo modo o mesmo símile (Gleichniss) pode ser usado para descrever a raça humana, que pode ser figurativamente (bildlich) representada como um compositum animal, uma forma de vida que os pólipos podem ser fornecidos como exemplos, especialmente aqueles que nadam, como o Veretillum, a Funiculina, e outros. Da mesma maneira que no caso destes, a porção da cabeça isola cada animal específico, mas a parte inferior com o estômago comum combina a todos como a unidade de um processo de vida, do mesmo modo também que o cérebro com sua consciência isola os indivíduos humanos. Por outro lado, a parte inconsciente, ou seja, a vida vegetativa com seu sistema ganglionar é uma vida comum a todos, na qual a consciência cerebral (Gehirnbewußtseyn) desaparece durante o sono, como o lótus noturno que fica submerso nos períodos de cheia." (SCHOPENHAUER, A. MVR II vol. 1, cap. 25, p. 473-474).

${ }_{128}$ PERELMAN, C. e OLBRECHTS-TYTECA, Tratado da Argumentação: A Nova Retórica, p. 423. 
Revista Voluntas: Estudos sobre Schopenhauer - Vol. 6, № 1 - $1^{\circ}$ semestre de 2015 - ISSN: 2179-3786 - pp. 44-84.

O caminho teórico trilhado por Schopenhauer para estabelecer o seu dogma imanente, se encontra no centro de uma tensão, a saber,

no meio entre a doutrina da onisciência dos dogmatismos anteriores e o desespero da crítica kantiana. As verdades importantes descobertas por Kant, contudo, com as quais os primeiros sistemas metafísicos foram demolidos, fornecem os dados e os materiais ao meu sistema." $" 129$.

A modificação da filosofia de Kant foi a marca de uma nova metafísica que pretendeu desvendar o mistério da unidade do homem com a natureza ${ }^{130}$. Dos primeiros manuscritos até a primeira edição do Mundo, observa-se o processo de reflexão do qual nasce toda sua filosofia. Nos diz o filósofo que "o mais digno de atenção é que já no ano de 1814 (aos meus 27 anos) todos os dogmas do meu sistema haviam sido estabelecidos" $" 131$.

Como vimos, a formação científica de Schopenhauer é significativa e se iniciou em 1809 na faculdade de medicina da Universidade Georgia Augusta em Göttingen, um dos mais importantes centros acadêmicos de pesquisa científica da Europa na época. Segundo nossa compreensão atual, é possível dizer que uma das mais importantes etapas na elaboração da metafísica da Vontade é primeiro contato com as ciências naturais em Göttingen, onde o filósofo conheceu um dos mais importantes cientistas alemães do período e professor de fisiologia da universidade, a saber, J. F. Blumenbach. A partir disso Schopenhauer inicia a sua reflexão sobre o corpo e desenvolve uma conexão entre metafísica e fisiologia. O "pensamento único"132 ou o principal dogma de Schopenhauer, foi elaborado em consideração aos conhecimentos obtidos pelo estudo das ciências naturais. Coincidentemente, a fisiologia e anatomia, ensinadas por Blumenbach como a "alma viva da história natural", se desenvolveram por meio da abordagem comparativa e da reflexão analógica. O conceito de Impulso formativo nasce de uma metodologia que, embora desempenhe uma função diferente na metafísica de Schopenhauer, possui com o filósofo alguma afinidade. Blumenbach sugeriu a

\footnotetext{
${ }^{129}$ SCHOPENHAUER, A. CK, p. 538-539.

${ }^{130}$ SCHOPENHAUER, A. MP III, 240 p. 620.

${ }^{131}$ SCHOPENHAUER, A. MP I, 208, p. 122.

${ }^{132}$ No prefácio à obra de 1818 , o filósofo explica a estrutura conceitual e a exposição de sua filosofia por meio da metáfora biológica do organismo, isto é, a estrutura de um pensamento único deve ser coesa na exposição, onde "cada parte tanto conserva o todo quanto é por ele conservada, nenhuma é a primeira ou a última, o todo ganha em clareza, mediante cada parte, e a menor parte não pode ser plenamente compreendida sem que o todo já o tenha sido previamente" (SCHOPENHAUER, A. MRV I, p.19-20).
} 
Schopenhauer a ideia de que é na matéria organizada onde natureza se apresenta com a maior complexidade e que a reflexão por analogia pode abrir o caminho para uma compreensão mais profunda do mundo natural. Isso se ajusta às pretensões de Schopenhauer, pois reforça a imanência de sua metafísica. O que diferencia a filosofia e ciência no que concerne à metodologia é a utilização do princípio de causalidade que tem sua aplicação legítima somente nas pesquisas empíricas e a amplitude do objeto de investigação de cada uma. Entretanto, isso não exclui uma coincidência metodológica entre a fisiologia comparativa ensinada por Blumenbach e a metafísica de Schopenhauer no que concerne à reflexão por analogia.

A importância das ciências naturais e mesmo os conhecimentos de Schopenhauer sobre elas foram, por vezes, questionados, ou mesmo criticados. Entretanto, essa interpretação não é consensual vindo a colidir diretamente com outras, incluindo a que aqui se apresenta, que procuraram observar a relevância da formação e das pesquisas científicas estudadas intensamente por Schopenhauer durante toda a sua vida $^{133}$. Tanto a formulação quanto o aprimoramento da obra do filósofo contam com um enorme esforço em estabelecer um contato entre metafísica e ciência e, neste sentido, o conhecimento das pesquisas empíricas mais atualizadas foram fundamentais para a consecução do argumento analógico de Schopenhauer. Os conhecimentos produzidos pelas ciências, apesar de não resolverem os problemas filosóficos são necessários para suscitá-los e as lições que Schopenhauer recebera em Göttingen "são muito necessárias e proveitosas para os filósofos"

A ciência corrigiu, ampliou e fundamentou uma compreensão do mundo, invalidando os pressupostos metafísicos vigentes e, com maior clareza e de forma mais correta e completa, sugeriu ao filósofo o problema próprio da metafísica, a saber, "o que é este mundo intuitivo tirante o fato de ser minha representação?"135. A fisiologia e a anatomia comparativas, sistematizando os conhecimentos empíricos sobre o organismo

\footnotetext{
${ }^{133}$ Maria Lúcia Cacciola (CACCIOLA, M. L. Schopenhauer e a questão do dogmatismo, p. 64.), por exemplo, argumenta que Schopenhauer, ao admitir "a unidade que se mostra pelo parentesco de todas as manifestações da natureza, já que provém de uma Vontade única", atribui "à anatomia comparada" o papel de "exibir tal princípio" no reino orgânico. Marco Segala se esforça no sentido de mostrar como as ciências naturais, especialmente a fisiologia, ofereceram a Schopenhauer uma enorme quantidade de conhecimentos, conceitos e métodos que foram se submetendo à reflexão e incorporação na metafísica da Vontade ao longo de toda a vida do filósofo. Ignazio Volpicelli e Fabio Grigenti também reconhecem o profundo interesse de Schopenhauer pelas ciências naturais e o papel fundamental que as mesmas desempenham na concepção de natureza do filósofo.

${ }^{134}$ SCHOPENHAUER, A. Correspondance complète, p. 68.

${ }^{135}$ SCHOPENHAUER, A. MVR I, § 5, p. 62.

Metafísica e ciência: a vontade e a analogia em Schopenhauer 
e os impulsos (Trieb) viventes e atuantes nele, abriram caminho e facilitaram o saber na direção da decifração schopenhaueriana do mistério do mundo em termos de essência íntima (Innerstes Wesen) e coisa-em-si (Ding an sich). Neste contexto e a partir do exposto nos interessou compreender o estatuto da analogia em Schopenhauer e o papel que ela desempenha no discurso sobre o problema da coisa-em-si.

Esta coisa-em-si sobre a qual Schopenhauer discursa, enquanto fruto de uma reflexão analógica, não pode ser considerada, no entanto, como um ser absoluto e necessário, um correlato de Deus, um princípio ontológico ou uma substância no sentido grego da palavra ${ }^{136}$. O conceito de coisa-em-si foi elaborado a partir de um método de reflexão por analogia inspirado nos estudos científicos de Schopenhauer e, enquanto tal, é parte de uma visão analógica da realidade que exclui o discurso sobre qualquer princípio ontológico transcendente. Não há um princípio ontológico, mas uma visão analógica do mundo a partir de uma vontade fisiologicamente manifesta no corpo e vivenciada de forma pré-reflexiva pelo sujeito do conhecimento, isto é, sob a exclusiva mediação dos seus atos sucessivos. $O$ próprio Schopenhauer na correspondência com Frauesntädt se esclarece sobre o assunto:

Nunca falei de uma SUBSTÂNCIA (Substanz) da vontade, porque eu não me abrigo, como os pseudo-filósofos, por trás de tais abstrações, para mim, substância é um mero sinônimo de matéria (Materie), para além disso, é um conceito ilegítimo. É verdade que em meu livro principal Volume 2, p. 204 se pode ler que "a vontade é a substância do homem"; entretanto, isso é para ser compreendido como "uma imagem e comparativamente." (bildlich und gleichnissweise) ${ }^{137}$.

A Vontade, portanto, é o substrato (Substrat) permanente das funções e atividades do corpo e "constitui o mais imediato de sua consciência, porém, como tal, sem aparecer completamente na forma da representação"138. E, "como uma palavra mágica, a vontade deve desvelar-nos a essência mais íntima de cada coisa na natureza”. Isto, apesar de metafórico e subjetivamente escolhido,

\footnotetext{
${ }^{136}$ Ver KOSSLER, M.: "A vida é apenas um espelho" - o conceito crítico de vida de Schopenhauer. ethic@ - Florianópolis, v. 11, n. 2, p. 17 - 30, julho de 2012; ATWELL, J. E.: Schopenhauer on the character of the world: the metaphysics of will. Berkeley: University of California Press, 1995, SEGALA, M. Schopenhauer, la filosofia, le scienze, Pisa, Edizioni della Normale, 2009; NEELEY, S.: Schopenhauer - A Consistent Reading. The Edwin Mellen Press. New York, 2003.

${ }^{137}$ SCHOPENHAUER, A. Correspondance complète, p. 366.

${ }^{138}$ SCHOPENHAUER, A. MVR I, §21, p. 168.
} 
de modo algum indica uma grandeza desconhecida, algo alcançado por silogismos, mas sim algo conhecido por inteiro, imediatamente, e tão conhecido que, aquilo que é vontade, sabemos e compreendemos melhor do que qualquer outra coisa, seja o que for ${ }^{139}$.

Nos diz o filósofo:

Tenho chamado a coisa-em-si, a natureza interna do mundo, a vontade, após o que é mais intimamente conhecido deste mundo para nós. Naturalmente esta é uma expressão subjetivamente escolhida, ou seja, em relação ao sujeito do conhecimento, mas tal consideração é essencial para comunicarmos o conhecimento. Ela é, portanto, infinitamente melhor do que se eu tivesse chamado de Brahm, Brahma, alma do mundo, ou qualquer outra coisa ${ }^{140}$.

Assim, enquanto o tempo for compreendido como a forma transcendental da consciência, "não há uma substância persistente, mas apenas a ocorrência de sucessivos atos singulares. [...] Não é possível introduzir qualquer substância persistente" ${ }^{\text {"141 }}$. A relação entre metafísica e ciência será, portanto, o registro sobre o qual a tese da Vontade considerada como coisa-em-si adquire algum significado para o discurso filosófico, já que, enquanto fruto de uma reflexão analógica e em sentido metafórico, a Vontade "só é a coisa-em-si de uma maneira RELATIVA"142.

\section{Referências bibliográficas}

SCHOPENHAUER, Arthur. Correspondance complète. Edition critique intègrale. Paris: Editions Alive, 1996.

. Diarios de viaje. Trad. Luis Fernando Moreno Claros. Madrid: Ed. Trotta, 2012. De La Quadruple Raiz Del Principio De Razon Suficiente. Trad. Leopoldo Eulogio Palácios. Madrid: Gredos, 1998. Der Handschriftliche Nachlass Band 5, Randschriften zu Büchern. Herausgegeben von Arthur Hübscher. München: Deutscher Taschenbuch Verlag, 1985.

Limited, 1988. Manuscript Remains, Vol I. Oxford, New York, Hamburg: Berg Publishers

Limited, 1988. Manuscript Remains, Vol II. Oxford, New York, Hamburg: Berg Publishers

Limited, 1988. Manuscript Remains, Vol III. Oxford, New York, Hamburg: Berg Publishers Limited, 1988. Manuscript Remains, Vol IV. Oxford, New York, Hamburg: Berg Publishers

\footnotetext{
139 SCHOPENHAUER, A. MVR I, §22, p. 170.

140 SCHOPENHAUER, A. MP IV, 148, p.169.

${ }^{141}$ SCHOPENHAUER, A. Metafisica della natura, p. 154.

${ }^{142}$ SCHOPENHAUER, A. Correspondance complète, p. 378. 
Revista Voluntas: Estudos sobre Schopenhauer - Vol. 6, № 1 - $1^{\circ}$ semestre de 2015 - ISSN: 2179-3786 - pp. 44-84. Metafisica della natura. A cura di Ignazio Volpicelli. Roma: Editori

Laterza, 1993.

Paulo: UNESP, 2005. O mundo como Vontade e como representação. Trad. Jair Barboza. São . O Mundo como Vontade e Representação, tomo II: Complementos vol. I-II. Trad. Eduardo Ribeiro da Fonseca. Curitiba: Ed. UFPR, 2014. Os pensadores vol. IV. Trad. Eudoro de Souza. São Paulo: Abril Cultural, 1973.

Trotta, 2006. Parerga y Paralipómena I. Trad. Pilar Lopez de Santa Maria. Madrid: Trotta, 2009. Parerga y Paralipómena II. Trad. Pilar Lopez de Santa Maria. Madrid: Retórica. Trad. Marcelo Silvano Madeira. São Paulo: Editora Rideel, 2007. Sobre a visão e as cores. Trad. Erlon José Paschoal. São Paulo: Nova Alexandria, 2005.

L\&PM, 2013. Sobre a Vontade na natureza. Trad. Gabriel Valladão Silva. Porto Alegre:

ATWELL, John E. Schopenhauer on the character of the world: the metaphysics of will. Berkeley: University of California Press, 1995.

BARTHA, Paul F. A. By Parallel Reasoning: The Construction and Evaluation of Analogical Arguments. New York: Oxford University Press, 2010.

BLÜMENBACH, Johann F. An essay on generation. Trad. Alexander Crichton. London: Printed for T. Cadell, Strand; Faulder, Bond Street; Murray, Fleet Street; and Creech, at Edinburgh, 1792.

Leipzig: Neueste Auflage, 1802. Handbuch der Naturgeschichte: nebst zwey Kupfertafeln. Frankfurt und Handbuch der vergleichenden Anatomie. Göttingen: Bey Heinrich Dieterich, 1805. Handbuch der vergleichenden Anatomie. Göttingen: Bey Heinrich Dieterich, 1805.

Christian Dieterich, 1781. Über den Bildungstrieb und das Zeugungsgeschäfte. Göttingen: Johann

BRANDÃO, Eduardo. A concepção de matéria na obra de Schopenhauer. São Paulo: Humanitas, 2008. CACCIOLA, Maria L. M. O. Schopenhauer e a questão do dogmatismo. São Paulo: Edusp - Fapesp, 1994.

CAMPBELL, Norman R. Physics The Elements. London: Forgotten Books, 2014.

GARDINER, Patrick. Schopenhauer. Trad. Ángela Saiz Sáez. México: Fondo de Cultura Económica, 1997.

GENTNER, Dedre; JEZIORSKI, Michael. The shift from metaphor to analogy in Western science. In: Metaphor And Thought (second edition). Andrew Ortony (ed.). New York: Cambridge University Press, 1993, p. 447-480.

GIL, Fernanco. Recepção da Crítica da Razão Pura: Antologia de escritos sobre Kant (1786-1844). Lisboa: Fundação Calouste Gulbenkian, 1992.

GRIGENTI, Fabio. Natura e rapresentazione: Genesi e strutura della natura in Arthur Schopenhauer. Napoli: La Cittá Del Sole, 2000.

HAMLYN, David W. Schopenhauer, The Arguments of the Philosophers. London: Routledge, 1999.

HANEGRAAFF, Wouter J. Esotericism and Academy: rejected knowledge in western culture. New York: Cambridge University Press, 2012

HERSCHEL, John. Preliminary Discourse On The Study Of Natural Philosophy. London: Printed for Longman, Brown, Green \& Longmans, 1851.

HESSE, Mary B. Models and Analogies in Science. United States of America: University of Norte Dame Press, 1970.

HÜBSCHER, Arthur. Arthur Schopenhauer Gespräche. Stuttgard: Friedrich Frommann Verlag (Günther Holzboog), 1971.

The philosophy of Schopenhauer in its intellectual context: Thinker against the tide. Trad. Joachim T. Baer and David E. Cartwright. New York: The Edwin Mellen Press, 1989.

INVERNIZZI, Giuseppe. Il Problema della cosa in sé e la concezione della Metafisica nella filosofia de Schopenhauer. In: ACME, Analli della Facoltá de Lettere e Filosofia dell'Università degli studi dell Milano, Vol. XXXVII 2 - Maggio-Agosto 1984. Milano: Cisalpino - Goliardica, 1984.

ITKONEN, Esa. Analogy as Structure and Process: Approaches in linguistics, cognitive psychology and philosophy of science. Amsterdam/Philadelphia: John Benjamins Publishing Company, 2005. 
JACOBI, Friedrich H. Sobre o Idealismo Transcendental. In: Recepção da Crítica da Razão Pura: Antologia de escritos sobre Kant (1786-1844). Fernando Gil (ed.). Lisboa: Fundação Calouste Gulbenkian, 1992, p. 99-111.

JANAWAY, Chritopher. Self And World in Schopenhauer's Philosophy. New York: Clarendon Press Oxford, 2007.

(ed.). Willing and Nothingness: Schopenhauer as Nietzsche's educator. New York: Clarendon Press Oxford, 1998.

JOHNSON, Mark (ed.). Philosophical Perspectives on Metaphor. Minneapolis: University of Minnesota Press, 1981.

KANT, Immanuel. Crítica da Razão Pura. $5^{\mathrm{a}}$ ed. Trad. Manuela Pinto dos Santos e Alexandre Fradique Morujão. Lisboa: Fundação Calouste Gulbenkian, 2001. Critique of Judgement. Trad. James Creed Meredith. New York: Oxford University

Press, 2007.

Correspondence. Trad. Arnulf Zweig. Cambridge: Cambridge University Press, 1999.

KOSSLER, Matthias. A vida é apenas um espelho - o conceito crítico de vida de Schopenhauer. In: Ethic@. Florianópolis, 30 de julho de 2012, vol. 11, nº 2, p. 17.

LENOIR, Timothy. The Gottingen School and the Development of Transcendental Naturphilosophie in the Romantic Era. University of Arizona: The Johns Hopkins University Press, 1981.

. The Strategy of Life: Teleology and Mechanics in Nieneteenth-Century German Biology. Chicago: The University of Chicago Press, 1982.

MAGNER, Lois N. A History of the Life Sciences. Third edition, revised and expanded. New York: Marcel Dekker, 2002.

MARINO, Luigi. I maestri della Germania - Göttigen 1770-1820. Torino: Piccola Biblioteca Einaudi, 1975.

NEELEY, G. Steven. Schopenhauer - A Consistent Reading. New York: The Edwin Mellen Press, 2003.

NIETZSCHE, Friedrich W. On Schopenhauer (I868). In: Willing and nothingness, Schopenhauer as Nietzsche's educator. Christopher Janaway (ed.). New York: Claredon Press Oxford, 1998, p. 258-265.

ORTONY, Andrew (ed.). Metaphor and Thougth $2^{\circ}$ ed. New York: Cambridge University Press, 1993.

PERELMAN, Chaim; OLBRECHTS-TYTECA, Lucie. Tratado da Argumentação: A Nova Retórica. Trad. Maria Ermantina Galvão G. Pereira. São Paulo: Martins Fontes, 1996.

PERRIER, Edmond. The Philosophy of Zoology Before Darwin. Trad. Alex McBirney. London/New York: Springer, 2009.

PLATÃO. Timeu-Crítias. Trad. Rodolfo Lopes. Coimbra: Centro de Estudos Clássicos e Humanísticos, 2011.

PRADO, Jorge L. P. Schopenhauer e a Metáfora da Vontade como coisa-em-si. In: Metafísica e Moral. Aguinaldo Pavão, Charles Feldhaus e José Fernandes Weber (orgs.). São Paulo: DWW Editorial, 2014, p. 189-233.

PRIESTLEY, Joseph. The History and Present State of Electricity, 2 vols. New York: Johnson Reprint, 1966.

REINHOLD, Karl L. Briefe Über die Kantische Philosophie e de Versuch einer neuen Theorie des Menschlichen Vorstellungsvermögen. In: Recepção da Crítica da Razão Pura: Antologia de escritos sobre Kant (1786-1844). Fernando Gil (ed.). Lisboa: Fundação Calouste Gulbenkian, 1992, p. 172-203.

RICHARDS, Robert J. Kant and Blumenbach on the Bildungstrieb: A Historical Misunderstanding. In: Stud. Hist. Phil. Biol. \& Biomed. Sci. Chicago, 2000, vol. 31, nº 1, p. 11-32.

RICOEUR, Paul. A Metáfora Viva $2^{\circ}$ Ed. Trad. Dion Davi Macedo. São Paulo: Edições Loyola, 2000.

SAFRANSKI, Rüdiger. Schopenhauer e os anos selvagens da filosofia. Trad. William Lagos. São Paulo: Geração Editorial, 2011.

SANTOS, Leonel R. A formação do pensamento biológico de Kant. In: Kant e a Biologia. Ubirajara Rancan de Azevedo Marques (org.). São Paulo: Editora Barcarolla, 2012, p. 17-81.

SCHULZE, Gottlob E. Enesidemo. In: Recepção da Crítica da Razão Pura: Antologia de escritos sobre Kant (1786-1844). Fernando Gil (ed.). Lisboa: Fundação Calouste Gulbenkian, 1992, p. 257-269.

SEGALA, Marco. Auf den Schultern eines Riesen Arthur Schopenhauer als Student Johann Friedrich Blumenbachs. In:,, ... die Kunst zu sehn“ Arthur Schopenhauers Mitschriften der Vorlesungen Johann Friedrich Blumenbachs (1809-1811). Jochen Stollberg und Wolfgang Böker (Hg.). Göttingen: Universitätsverlag Göttingen, 2013.

Olschki, 1998. I fantasmi, Il cervello, L'anima: Schopenhauer, l'occulto e la scienza. Firenze: Leo S.

La metafora scientifica in Schopenhauer. In: Segni e percorsi dela modernità. Saggi in onoredi Paolo Rossi. Dipartimento di studi storico - social e filosofici, Siena: Università degli Studi di 
Siena, 2000, p. 123-156.

. Schopenhauer, la filosofia, le scienze. Pisa: Edizioni della Normale, 2009.

The Role of Physiology in Schopenhauer's Metaphysics of Nature. In: Schopenhauer Jahrbuch, 93 (2012), p. 327-334.

SEGALA, Marco; DE CIAN, Nicoletta. What is will?. In: Schopenhauer Jahrbuch, 83 (2002), p. 13-42, disponível em http://www.item.ens.fr/index.php?id=577242.

SILVA, Marcos. On analogical arguments: Organizing logical and conceptual problems in sections 18 and 19 of Schopenhauer's The World as Will and Representation. In: Revista Voluntas: Estudos sobre Schopenhauer. Rio de Janeiro, $2^{\circ}$ semestre 2011, vol. 2, nº 2, p. 185-215.

STAMMBERGER, Ralf M. W. On Analogy: An Essay Historical and Systematic. Frankfurt am Main; Berlin; Bern; New York; Paris; Wlen: Peter Lang, 1995.

STOLLBERG, Jochen; BÖKER, Wolfgang. (Hg.). „, .. die Kunst zu sehn“ Arthur Schopenhauers Mitschriften der Vorlesungen Johann Friedrich Blumenbachs (1809-1811). Göttingen: Universitätsverlag Göttingen, 2013.

TORRES FILHO, Rubens R. Ensaios de filosofia ilustrada. São Paulo: Editora Brasiliense, 1987.

VOSNIADOU, Stella; ORTONY, Andrew (ed.). Similarity and Analogical Reasoning. New York: Cambridge University Press, 1989.

ZILBERMAN, David B. Analogy in Indian and Western Philosophical Thought (Boston Studies in the Philosophy of Science). The Netherlands: Published by Springer, 2006.

Recebido: 02/07/15

Received: $07 / 02 / 15$

Aprovado: $15 / 08 / 15$

Approved: 08/15/15 